\title{
Advancement of sweep zones in waterflooding: conceptual insight based on flow visualizations of oil-withdrawal contours and waterflood time-of-flight contours using complex potentials
}

\author{
Ruud Weijermars ${ }^{1} \cdot$ Arnaud van Harmelen $^{1,2}$
}

Received: 28 June 2016/Accepted: 24 October 2016/Published online: 8 December 2016

(c) The Author(s) 2016. This article is published with open access at Springerlink.com

\begin{abstract}
Sweep zones are traced in synthetic reservoir models of waterflood advancement based on potential functions. Time-of-flight contours, oil-withdrawal contours and streamlines corresponding to fluid withdrawal paths are visualized. The effects of differential well rates on waterflood sweep regions for a range of well architectures are systematically investigated using reservoirs that are continuous isotropic with and without impervious fault barriers. Complex potentials are capable of solving the drainage path for any constellation of producer and injection wells, accounting for any discontinuities that affect the flow path and productivity of the wells. Flood patterns are visualized for a series of doublets and 7-spot well patterns. Loss of planned drainage symmetry occurs when an undiscovered fault barrier obstructs and diverts the waterflood. Our method is assumed effective in illustrating the value of analytical streamline simulations for first-order assessment of sweep patterns in hydrocarbon field produced with waterflooding. The critical impact of injection rates and fault barriers on the shape of the waterflooding patterns is visualized in detail. The analytical streamline simulator allows tracing of the respective flow paths of displacing oil and water in the reservoir and visualizes both oil-withdrawal contours and waterflood time-of-flight contours. Generic rules are formulated to aid sweep maximization both prior to drilling and during the surveillance of producing wells.
\end{abstract}

Ruud Weijermars

R.Weijermars@TAMU.edu

1 Harold Vance Department of Petroleum Engineering, Texas A\&M University, 3116 TAMU College Station, College Station, TX 77843-3116, USA

2 Department of Applied Mathematics, Delft University of Technology, Mekelweg 4, 2628, CD, Delft, The Netherlands
Keywords Reservoir simulations - Complex potentials · Improved oil recovery $\cdot$ Flood management $\cdot$ Well surveillance

\author{
Abbreviations \\ AEM Analytical element method \\ $\beta \quad$ Fault orientation angle \\ $d \quad$ Distance of well pair in doublet \\ $\Delta t \quad$ Time step \\ EOR Enhanced oil recovery \\ FD Finite difference \\ $K \quad$ Permeability \\ $K \quad$ Number of injectors \\ $l \quad$ Fault half-length \\ $\delta_{\mathrm{s}} \quad$ Conformal mapping angle \\ MLA Multivariate lower algorithms \\ $h \quad$ Reservoir thickness \\ $m_{s} \quad$ Well strength \\ $n \quad$ Number of producers \\ $Q^{p} \quad$ Flux of producer \\ $Q^{i} \quad$ Flux of injector \\ RF Recovery factor \\ $t \quad$ Runtime \\ $V(z) \quad$ Velocity field \\ WAF Well allocation factor \\ $z \quad$ Complex variable \\ * Non-dimensional form of asterisked parameter
}

\section{Introduction}

Although streamline simulations based on analytical methods face certain limitations, one of the strengths is fast tracing of fluid particle paths. Analytical streamline 
simulations have improved our insight of reservoir behavior since the early work of Muskat (1949a, b) of Gulf Oil Corporation, based on previous efforts (a.o., Wyckoff et al. 1933; Muskat and Wyckoff 1934). The basic merit of streamline simulations is that well productivity can be explained as the flux of fluid carried through the streamtubes outlined by discrete bundles of streamlines into the well (Hauber 1964; Morel-Seytoux 1965; Higgins et al. 1964; LeBlanc and Caudle 1971; Martin and Wegner 1979; Abou-Kassem and Aziz 1985; Cox 1987; Datta-Gupta 2000; Datta-Gupta and King 2007). Excellent review of streamtube reservoir models is given in Thiele (1994, 1996). Field experiments have demonstrated that the relationship between injected fluid and production is not always simple (Heidt and Follensbee 1971; Martin et al. 1973). When particle paths that transport water reach and oil well after some time, the well will start to produce a proportionate admixture of water and oil. When many water injectors interact with producer wells, there is a high risk of over-flooding the producer wells. This occurs when injected water pushes oil away from the producers rather than into it, hence killing a producer prematurely rather than achieving the intended enhanced production. Examples of such effects are included in our below flood simulations.

An analytical streamline simulator used in our present study has been previously applied to investigate reservoirs with a natural far-field flow and its effect on the integrity of doublets and direct line drives (Weijermars and Van Harmelen 2016). The occurrence of any far-field flow is excluded in the doublet flow visualization developed in the present study. The flood simulations reported below reveal that even when a far-field flow is absent, the fluid flow paths of doublets appear quite complex. We realized it is prudent to distinguish three fundamental types of sweep zones, for which we make use of two types of time contours: one set of contours showing advancement of the flood front emanating from the injection well, spaced for regular time intervals (blue contours in this study), and another set of oil drainage contours around the production wells detailing expansion of the drainage area over time (red contours in our study). When the two sets start to overlap, the dynamic evolution of each type of sweep zone can be described in certain detail (see below).

Our analytical streamline simulator is based on a series of complex potentials which are closed-form solutions for the respective flow elements. The simulator has been validated by comparison with an independent streamline tracing method based on nonlinear differential equations (Weijermars et al. 2016). The analytical simulator can account for a wide range of initial states, boundary conditions, and transient processes that affect the parameters controlling the fluid flow path during waterflooding. The number of wells and/or geometry of the well patterns, injection and production profiles, and spatial variations in reservoir properties (e.g., heterogeneities, discontinuities) are only limited by computing power. The simulator can visualize waterflooding patterns using any conceivable drilling pattern and variable injection rates. There is no practical constraint for the finite number of wells. Possible flow barriers such as an impervious fault (for example, rendered impermeable due to clay smear and fault gauge) can also be included. We have modeled elsewhere the impact on waterflood sweep of discrete discontinuities like abrupt jumps in reservoir permeability and due to impervious fault barriers in unbounded reservoirs (Weijermars et al. 2016) and in bounded reservoirs (Nelson et al., submitted).

When streamline visualizations based on complex potentials were combined with emerging computer power in the 1970s (Doyle and Wurl 1971), microprocessor capacity was a limiting factor for flow visualizations. Although reservoir simulation technology has since advanced to include PVT properties and multiphase flow effects, some simple reservoirs with unit mobility ratios may still benefit from insights based on flow simulations incorporating analytical methods. Continuous development and merging of analytical with semi-analytical boundary element solution methods have advanced the solution range.

Algorithms used here are partly similar to those used in earlier studies using potential flow, and our emphasis is on flow visualization. At the same time, while acknowledging limitations exist, we highlight below that some limitations presumed in the past in fact do no longer apply thanks to advances of both pristine analytical methods and expansion into semi-analytical methods (see below). For example, reservoir simulations based on potential functions were previously considered limited due to requirement of homogeneous properties throughout the reservoir (DattaGupta 2000). Advances have been made with the analytical element method (AEM) and discontinuities like impervious barriers, leaky faults and heterogeneities can be incorporated in such models (Strack 1989; Haitjema 1995).

The present study intends to showcase the versatility of streamline visualizations based on closed-form solutions for a number of instructive, synthetic cases. We start out with a comparison of regular well patterns (2-, 7-spot) to highlight the dynamic development of three fundamental types of sweep zones, first distinguished in our study. In addition, the distortional effect of impermeable faults on drainage regions, using regular, systematic well patterns for clarity, is visualized. Scaling of flight times and drainage volumes for a specific field application is possible applying scaling rules to the non-dimensional quantities used in our model.

This research paper proceeds as follows. "Basic assumptions and key algorithms" section details the basic 
assumptions and key algorithms used in our simulator. "Model results for doublets (direct line drives)" section presents the results of the systematic flow visualizations for doublets (faulted and unfaulted, balanced, underbalanced and overbalanced injection) all illustrated with scaled oil drainage and flood-front advancement contours. "Model results for 7-spot well patterns" section proceeds with a range of 7-spots (singles and multiples); arbitrary well patterns and infill drilling are given in "Arbitrary producer well patterns, infill drilling and peripheral flooding" section. A final discussion of the principal results and limitations ("Discussion" section) is followed by brief conclusions ("Conclusions" section).

\section{Basic assumptions and key algorithms}

\section{Model assumptions}

We confine our study to a relatively thin homogeneous reservoir within a sub-domain of a much larger reservoir, with an areal extent far beyond the immediate area of initial production. In keeping with the Dykstra-Parsons model, the reservoir is assumed to occur in discrete layers separated by intercalations of impervious beds which preclude the communication of any vertical pressure gradients. Vertical pressure gradients do not occur in our 2D sweep study. The displacement of oil by water is not a simple drainage process, because oil imbibition (non-wetting in the pore space) affects the volumetric sweep of the reservoir. Wettability effects and true residual oil left in the pore space after sweep passage are neglected by simplifying Darcy flow. Relative permeability effects included in a Buckley-Leverett model are not considered in our paper. A Buckley-Leverett model uses a transport equation for immiscible displacement of the two phases which is justifiable when assuming a single layer reservoir (homogeneous reservoir properties, capillary pressure effects are negligible, linear displacement and no free-gas). The Dietz model conditions are assumed fulfilled for piston-like oilwater interface displacement that outpaces any gravity forces that would distort the interface during flooding. The capillary pressures of any connate water and oil are different, which would affect the displacement of the oil by injection waterdrive at the pore-space scale, but are neglected in our model. The permeability of porous media can be characterized on a certain modeling scale in numerous mathematical ways (e.g., Rubinstein and Torquato 1989), the most concise still being the description of fluid permeability based on Darcy's law (e.g., Bear 1972; Bar-Meir 2013).

In most waterflood models, a critical assumption is that all offset oil balances with the injected water volume. The streamline method is an advance over previous insight in that substantial flow may occur between wells outside the predefined well pattern due to reservoir heterogeneity, anisotropy, and discontinuities such as faults (King et al. 1993; Moreno et al. 2004; Shin and Sharma 2014). Wellrate allocation factors (WAFs) can be based on streamline models that quantify the relative fluid volumes moving along streamlines from injector to producer wells. Another basic assumption is that streamlines are initially not affected by the mobility ratio (Higgins and Leighton 1962a, b). To gain a better overview of injector effectiveness, injector-centered flow patterns were proposed (Batycky et al. 2005). The so-called offset oil then is produced by other wells connected to the injector, considered to account for all oil volume produced. A complementary method to WAFs is the scaling of well interconnectivity using coefficients based on multivariate lower algorithms (MLA) analysis of the waterflood advance rates (Albertoni and Lake 2003). Directional peaks in the interconnectivity coefficients highlight high-permeability channels in the reservoir and vice versa. An advantage of flow-based allocation (Batycky et al. 2005) over allocation factors based on fixed streamtubes are socalled time-of-flight models (Samier et al. 2001), which account in the sum of well capacitance for transient flow effects such as well shut-ins, infill drilling, changes in injection rate and/or field pressure decline (e.g. Tiab and Dinh 2013). Our analytical models use an Eulerian particle tracing algorithm that can account for such transient flow effects (see "Key algorithms" section).

We use valid solutions of linear differential equations that describe reservoir flow for a wide range of well patterns, initial conditions and physical properties of the reservoir. Our method can track an unlimited number of particles along the oil-water front, so that its displacement can be mapped with high resolution. In our visualizations, only few streamlines are highlighted for clarity of presentation, but migration of the oil-water front contour is based on dense cluster-tracking of particles. The frontal waterflood contour is assumed to maintain an oil-water interface without the occurrence of diffusion effects or viscous fingering. In two fluid systems with movable interfaces, such as water-oil and oil-gas, hydrodynamic coupling at the interface occurs for the kinematic and dynamic conditions (Dougherty 1963; Dougherty and Sheldon 1964; Sheldon and Dougherty 1964; Abbaszadeh-Dehghani 1982; Masukawa and Horne 1988; Peddibhotla et al. 1997).

\section{Key algorithms}

Drilling patterns comprising wells acting as sources (injectors) and/or sinks (producers), located at $z_{s}$, can be described in any location $z$ of the complex plane 
representation of a reservoir. The reservoir is assumed to have relatively narrow thickness as compared to its lateral dimensions; the $z$ plane of complex coordinates is oriented parallel to the direction of the reservoir's lateral extent. The reservoir fulfills our black oil assumption and complies with the requirement of incompressible fluid and irrotational flow. A valid solution of the source/sink flow field due to the injector and producer wells, with strengths $m_{s}$ $\left(\mathrm{m}^{2} \mathrm{~s}^{-1}\right.$; using SI units), can be concisely represented by the following vector field (Weijermars et al. 2016):

$V_{1}(z)=\sum_{s=1}^{n} \frac{m_{s}}{z-z_{s}}$

The volumetric flow rate $Q\left(\mathrm{~m}^{3} \mathrm{~s}^{-1}\right)$ of each well can be obtained by multiplying well strength $m_{s}$ with the reservoir thickness $h(\mathrm{~m})$ according to $\mathrm{Q}=2 \pi m h$ (see appendix $\mathrm{B} 1$ in Weijermars 2014).

We adopt a vector field description of a source/sink flow field including a fault with orientation $\beta$ (measured counter-clockwise from the real axis) and half-length $l(\mathrm{~m})$. The fault barrier is modeled using a complex potential based on the circle theorem and the Joukowski transformation (Weijermars and van Harmelen 2016). The conformal mapping operations used to model source and sink flows affected by a fault requires the introduction of a mapping angle $\delta_{s}$ (expressing the rotation angle of the well position relative to the fault center $\left(z_{f}\right)$ during one of the mapping operations), which differs for each well location.

$$
\begin{aligned}
& V_{2}(z)=
\end{aligned}
$$

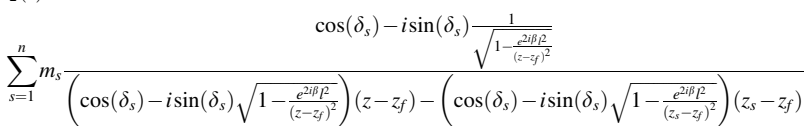

Stagnation points occurring in the flow field $V_{1}(z)$ can be found by solving $V_{1}(z)=0$. For example, in the case of a doublet with wells located at $z_{1}$ and $z_{2}$, the location of the stagnation point is:

$z_{s p}=\frac{m_{1} z_{2}+m_{2} z_{1}}{\left(m_{1}+m_{2}\right)}=z_{2} \frac{m_{1}}{\left(m_{1}+m_{2}\right)}+z_{1} \frac{m_{2}}{\left(m_{1}+m_{2}\right)}$

Expression (3) is valid only if $m_{1} \neq m_{2}$, because the stagnation point vanishes when the doublet is balanced. For actual modeling purposes, we use non-dimensional units (denoted by asterisked quantities). All simulations presented in this study are universally scaled by normalization using the rules of dimensional analysis (e.g., Weijermars and Schmeling 1986; Hewett and Behrens 1991; Bar-Meir 2013) and can be translated to dimensional units for specific applications.

Figures in this study have been generated using MATLAB. The time-of-flight contours (TOFCs) are tracked for water advance front and corresponding oil- withdrawal to the producer wells. The discretization time step $\Delta t^{*}$ can be very small and follows a first-order Eulerian scheme (Zandvliet 2008):

$\dot{z}^{*}\left(t^{*}\right) \approx \frac{z_{k+1}^{*}-z_{k}^{*}}{\Delta t^{*}}$

The state vector $z^{*}$ after $k$ time steps is given by $z_{k}^{*}:=z^{*}(k \Delta t)$. Individual streamlines are traced by first choosing an initial position, $z_{0}^{*}$, from which the tracing starts at the non-dimensional time $t_{0}^{*}=0$. The position of the tracer at non-dimensional time $t_{1}^{*}$, i.e. after one non-dimensional time step $\Delta t^{*}$, is denoted by $z_{1}^{*}\left(t_{1}^{*}\right)$ and can now be calculated as:

$z_{1}^{*}\left(t_{1}^{*}\right)=z_{0}^{*}\left(t_{0}^{*}\right)+v\left(z_{0}^{*}\left(t_{0}^{*}\right)\right) \cdot \Delta t^{*}$

In the above notation $v\left(z_{0}^{*}\left(t_{0}^{*}\right)\right)$ is the velocity of the particle located at position $z_{0}^{*}$ at non-dimensional time $t_{0}^{*}$. The velocity is calculated using velocity potential functions as described in Eqs. (1) and (2). Smooth streamlines are obtained for small values of $\Delta t^{*}$ (e.g. $\Delta t^{*}=0.01$ ), but a stronger source, sink or far-field flow requires a smaller $\Delta t^{*}$. Generalizing this concept, the position of a tracer at non-dimensional time $t_{j}^{*}$ is given by:

$z_{j}^{*}\left(t_{j}^{*}\right)=z_{j-1}^{*}\left(t_{j-1}^{*}\right)+v\left(z_{j-1}^{*}\left(t_{j-1}^{*}\right)\right) \Delta t^{*}$

Steady-state well rates are used in what follows to be able to focus on the effects of variations in volume balance of the waterflood program. However, time-dependent rates can be readily handled by our code. Such transient flight path adjustments are useful for many practical applications (e.g., Pizarro and Branco 2012). For example, variable source rates were already used in another application of our flow visualization method, which explains the variety in the shapes of terrestrial gravity flows (Weijermars et al. 2014).

\section{Three zones in waterflood system}

Figure 1 highlights common well patterns traditionally used for onshore water-injection-assisted oil production such as direct line drives, staggered line drives, 5-spot networks and 7-spot networks. Field development by drilling such fixed well patterns is often practical for operational diligence. An additional advantage is that in surveillance and evaluations of reservoir performance, it becomes quickly apparent which sub-domains deviate from the anticipated well productivity and any adverse impact on the recovery factor must be remediated. Some wells may have been allocated too high injection rates in proportion to the local anomalies in reservoir conductivity. All drainage volumes and water saturation factors can be quantified by our method, but these aspects are excluded for brevity.

Some fundamental aspects of oil drainage contours, streamlines symmetry patterns and flood patterns are 
Fig. 1 Sketch of well patterns commonly used in field development with injection wells for waterflooding (adapted from http://www.petrowiki.org/ waterflooding)

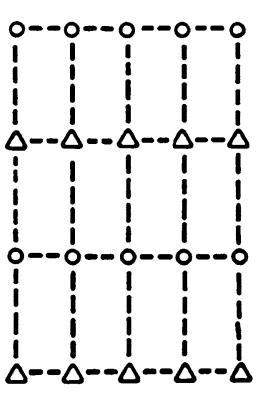

Direct line drive

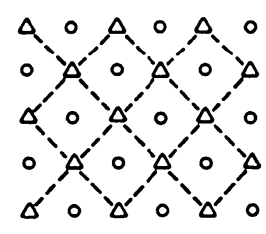

Regular five-spot

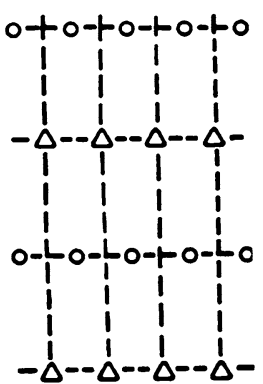

Staggered line drive

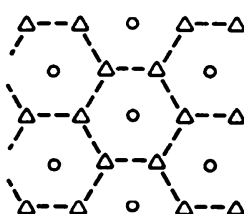

Regular seven-spot

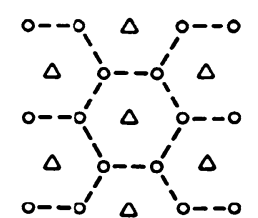

Inverted seven-spot

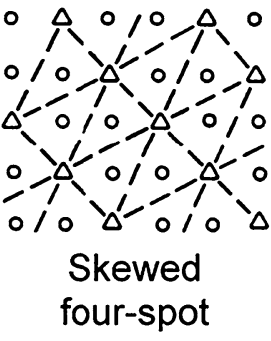

Two-spot<smiles>C1CCOCCCOC1</smiles>

Three-spot
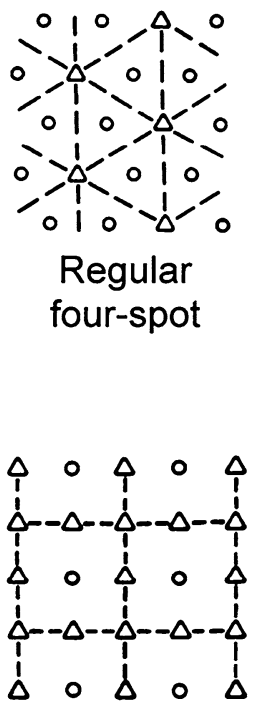

Regular nine-spot

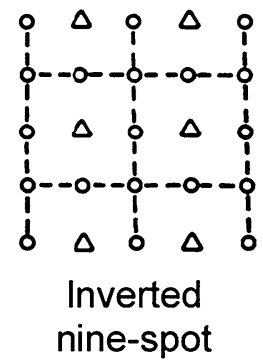

briefly explained here. When no flood is applied, the oilwithdrawal contours in a continuous (non-faulted), homogeneous and isotropic reservoir remain unperturbed and are shaped as concentric circles centered around the production well with decreasing spacing going outward for contours of equal time lapse (Fig. 2a). However, when an injector well is activated in the reservoir space drained by the production well, oil-withdrawal contours will loose their concentriccircle symmetry and become distorted near the injector well (Fig. 2b).

The progressive advance of the waterflood front toward the producer well of any doublet of an otherwise homogenous reservoir is controlled by the well spacing and their relative rates. The case of Fig. $2 b$ assumes a doublet with equal strength for the pair of injection and production wells. The complexity of fluid movement becomes apparent even for this simple flooding program using a single spaced doublet. Three distinct zones can be distinguished in any 2-spot waterflood system (annotated in Fig. 2b). Zone 1 (dark-gray shaded) outlines a reservoir section where the original oil has already been drained by the production well and may currently be occupied by oil brought in along streamlines from the outer region. Oilwithdrawal patterns are scaled with red contours, demarcating progressive drainage timelines. Zone 2 contains floodwater and represents a reservoir section (previously part of Zone 1 before the arrival of the flooding front) where the original oil already moved into the production well ahead of the water front. Remember that the outermost red contour around the producer wells outlines the boundary of the drainage region containing oil that was last swept into the producer for the total runtime shown. Zone 3 contains advancing floodwater from the injector well (blue contours), which is assumed to sweep some residual oil into the producer well. The three distinct sweep regions (Zones 1-3) co-exist and grow at expense of each other. Figure 2c shows a more advanced stage of flooding using a stronger injection rate.

The brief example of Fig. 2 highlights that the flow path and fluid displacement of the 2-spot direct line drive (spaced doublet) is far from simple. Because the doublet is both commonly applied in numerous field projects as well 
(a)

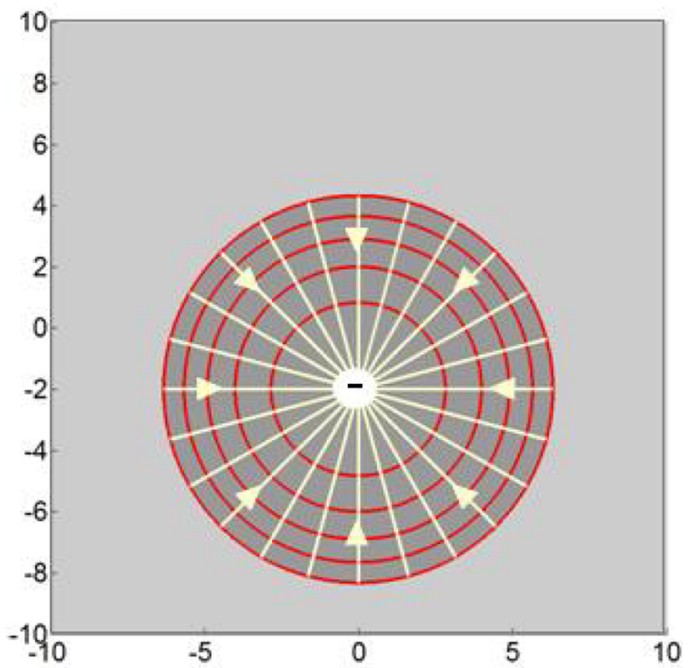

(b)

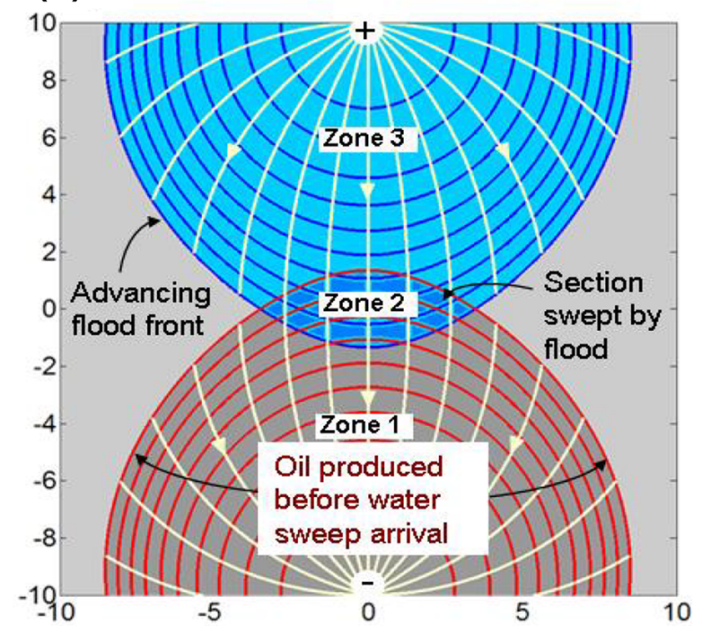

(c)

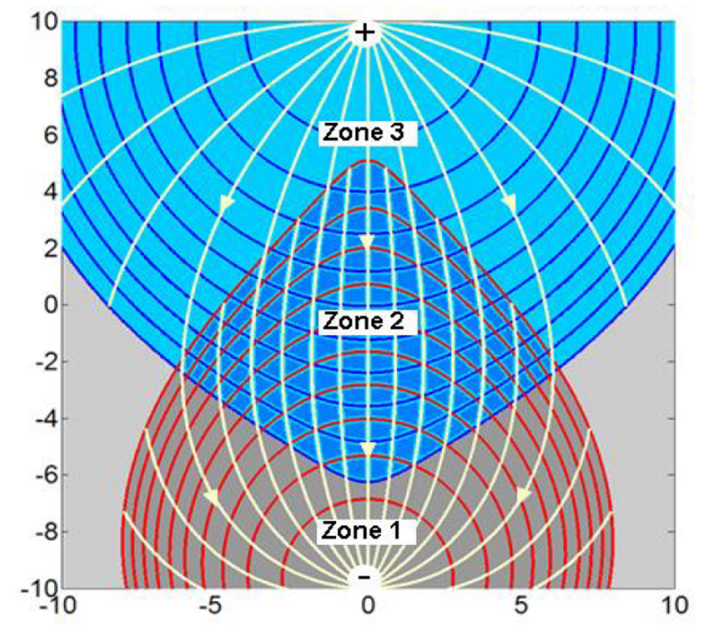

४Fig. 2 Top view of horizontal oil reservoir (light gray space) initially produced with one vertical well. Red contours oil-withdrawal contours showing expanding outline of region that already contributed oil to the production well. Streamlines for oil in yellow. The decrease in spacing of the oil-withdrawal contours is here scaled for constant production rate; a declining well rate would result in faster narrowing of the contour spacing going outward. b, $\mathbf{c}$ Widely spaced doublets $\left(d^{*}=20\right)$ with water flood advance in blue. Streamlines for advancing waterflood are portrayed by white curves. b Balanced injection $\left(m *\right.$ injector $=+1 ; m^{*}$ producer $=-1$, runtime $t^{*}=40$, and contour spacing $\left.t^{*}=4\right)$. c Unbalanced injection $(m *$ injector $=+2 ; m^{*}$ producer $=-1$, runtime $t^{*}=40$, and contour spacing $\left.t^{*}=4\right)$

as used in the conceptualization of well behavior and fluid migration paths for both oil wells and geothermal energy projects, we systematically studied the development of the sweep region for both equal and different rates of injector and producer wells. However, volume balance between the well pairs may not be necessarily assured in real field situations, and the balance between the fluid volume produced and injected by the well pair of the doublet may differ. These so-called unbalanced doublets may occur in the real world due to a variety of conditions: different wellbore diameters for injector and producer wells or when their respective tubular lengths differ, when the black oil assumption is a poor approximation for the real reservoir (which occurs when pore space is partly void, only partially filled with oil) or when different pressures between injector and producer well occur due to storage of injection fluid. Transient Darcy flow may delay communication of injector well with the producer well. Over- and underbalanced injection/production rates may occur when voidage replacement ratios are different from one, which means some of the fluid is either lost or gained from the far-field. There may be associated re-pressurization if the system is compressible, if incompressible net loss or gain of injection fluid is the corresponding response.

In a bounded system, overbalancing or underbalancing may result in, respectively, re-pressurization or depletion of the reservoir as a measure of material balance. Such effects are stronger and may alter the flow pattern visualized in the present study for unbounded reservoir systems. In a 3 well case (IPP or IIP), the allocation of fluids will stay closer to proportional allocation only when reservoir boundaries are nearby to approach a closed system. Nontrivial allocations occur when at least two injectors (or more) and two producers (or more) are located in either a larger finite or infinite domain. WAF $=1$ is an unlikely case when equal volume production is intended as some fluids may come from the far-field. 
All flow visualizations in our paper include time contours for both the flood advancement and the oil-withdrawal. Such time contours capture the full time-series as each contour inward from the final contour shows a preceding stage. For users less familiar with reading such time-of-flight contours, separate time-series are merited. Although time-series are encoded in the flood front and oil drainage contours used in each image, separate images are produced for several key cases in this study to aid the interpretation.

\section{Definitions of well balance}

The fraction of fluid flux in a producer due to the surrounding injectors is commonly expressed by well allocation factors (WAFs). Traditionally, the $\mathrm{WAF}^{p \leftarrow i}$ is taken as the ratio of the flux due to a particular injector $Q^{p \leftarrow i}$ and the total flux of the producer $Q^{p}$ (Batycky et al. 2005):

$\mathrm{WAF}^{p \leftarrow i}=\frac{Q^{p \leftarrow i}}{Q^{p}}$

We define balanced injection as a water flooding program where the sum of all individual producer fluxes $\left(Q^{p}\right)$ equals the sum of all individual injector fluxes $\left(Q^{i}\right)$. This implies for a two-spot pattern with one producer and one injector that the WAF satisfies:

$\mathrm{WAF}^{p \leftarrow i}=\frac{Q^{p \leftarrow i}}{Q^{p}}=1$ and $Q^{p}=Q^{i}$

Balancing an inverted three-spot pattern (with one producer and two injectors) requires

$\sum_{i=1}^{2} \mathrm{WAF}^{p \leftarrow i}=\sum_{i=1}^{2} \frac{Q^{p \leftarrow i}}{Q^{p}}=1$ and $Q^{p}=\sum_{i=1}^{2} Q^{i}$

One producer with $n$ peripheral injectors will be balanced when:

$\sum_{i=1}^{n} \mathrm{WAF}^{p \leftarrow i}=\sum_{i=1}^{n} \frac{Q^{p \leftarrow i}}{Q^{p}}=1$ and $Q^{p}=\sum_{i=1}^{n} Q^{i}$

When drilling patterns with $n$ injectors and $k$ producers, a balanced flooding must satisfy the following conditions:

$$
\begin{aligned}
\sum_{p=1}^{k} \sum_{i=1}^{n} \mathrm{WAF}^{p \leftarrow i}= & \sum_{p=1}^{k} \sum_{i=1}^{n} \frac{Q^{p \leftarrow i}}{Q^{p}}=k \text { and } \\
& \sum_{p=1}^{k} Q^{p}=\sum_{i=1}^{n} Q^{i}
\end{aligned}
$$

The latter condition in expression (6d) states that the sum of fluxes of all individual producers equals the sum of all individual injector fluxes. Furthermore, it should be noted that the WAF expression balances fluid fluxes, but does neither specify the arrival time of the waterfront nor the actual fraction of water in the producer, which will be time-dependent. One would need to distinguish between arrival times of oil fluxes and water fluxes to enable allocation of water-cut ratio to the producer based on WAFs (e.g., Nilsen and Lie 2009).

Overbalanced injection occurs when the sum of all injector fluxes exceeds the sum of all producer fluxes. Consequently, overbalanced WAFs have to fulfill:

$\sum_{p=1}^{k} \sum_{i=1}^{n} \mathrm{WAF}^{p \leftarrow i}=\sum_{p=1}^{k} \sum_{i=1}^{n} \frac{Q^{p \leftarrow i}}{Q^{p}}=k$ and $\sum_{p=1}^{k} Q^{p}<\sum_{i=1}^{n} Q^{i}$

The WAF expression (7) of the overbalanced case is equal to the WAF expression (6d) of the balanced case, but does not account for all fluid displaced by the injectors. A fraction of the injection water bypasses the producer wells (see later simulations), because the sum of all individual injector fluxes is larger then the sum of all individual producer fluxes. Arrival times of oil fluxes and water fluxes need to be distinguished (as visualized in our study) to enable allocation of water-cut ratio to the producer based on WAFs. In the case of overbalanced injection, water will eventually completely flood the producer well, and excess water will be stored elsewhere in the reservoir.

Underbalanced injection is defined as a water flooding program where the sum of all injector fluxes is less then the sum of all producer fluxes. Consequently, underbalanced WAFs require:

$\sum_{p=1}^{k} \sum_{i=1}^{n} \mathrm{WAF}^{p \leftarrow i}=\sum_{p=1}^{k} \sum_{i=1}^{n} \frac{Q^{p \leftarrow i}}{Q^{p}}<k$ and $\sum_{p=1}^{k} Q^{p}>\sum_{i=1}^{n} Q^{i}$

The WAF expression (8a) of the underbalanced case shows that injectors supply only a fraction of the fluid flux in the producers. For example, in the case of an underbalanced two-spot:

$\mathrm{WAF}^{p \leftarrow i}=\frac{Q^{p \leftarrow i}}{Q^{p}}<1$ and $Q^{p}>Q^{i}$

In the case of underbalanced injection, all floodwater will eventually become part of the production flux, but one or more producers will never reach $100 \%$ water cut, because far-field oil can still be drained (unless channeling of floodwater occurs). We use synthetic reservoir scenarios of 2-spot ("Model results for doublets (direct line drives)" section), 7-spot drilling patterns ("Model results for 7-spot well patterns" section) and random infill wells ("Arbitrary producer well patterns, infill drilling and peripheral flooding" section) to illustrate the effect of various injection balances. 


\section{Model results for doublets (direct line drives)}

\section{Doublets in continuous reservoirs}

Figure $3 \mathrm{a}-\mathrm{c}$ provides a time-series for a spaced doublet with equal injection and producer well rates. The outlines of the advancing flood front at different times are given by the time contours, which in Fig. $3 \mathrm{~d}$ are spaced for equal time lapses. Zone 1 outlines the reservoir portion where original oil has already been evacuated (dark gray) and produced by the well. Zone 1 would have been depleted by the well were it not replenished with far-field oil (light gray) as far as such oil is mobile without flooding. Zone 2 outlines the reservoir part previously occupied by Zone 1 but now already swept by the advancing flood (dark blue), which has started to mix water in the production well. Crucially, the region occupied by Zone 2 is the only portion of the reservoir where water sweep has passed through the pore space and directly displaced oil via streamtubes connected to the producer well. Zone 3 is the reservoir portion flooded (light blue), but that flood region has not yet contributed to sweep oil into the producer well for the time step visualized. Note that floodwater also pushes some oil farther away from the producer rather than toward it.

Figure $4 \mathrm{a}-\mathrm{c}$ highlight the late stage continuation of the flooding program with the doublets of Fig. 3a-c. The producer receives progressively larger quantities of injected water due to which the well's water-cut increases for longer runtimes.

The early stages of the flood sweep development for underbalanced flooding are visualized in Fig. 5a-c. This shows a relatively thin snout develops first before the broader flood front engulfs the producer. Again, the (a)

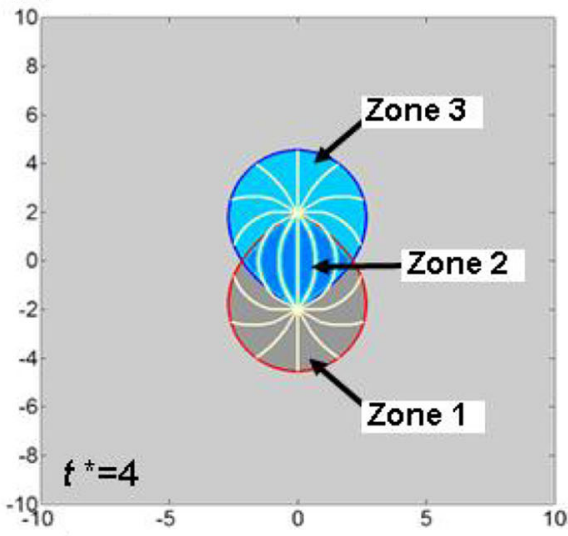

(b)

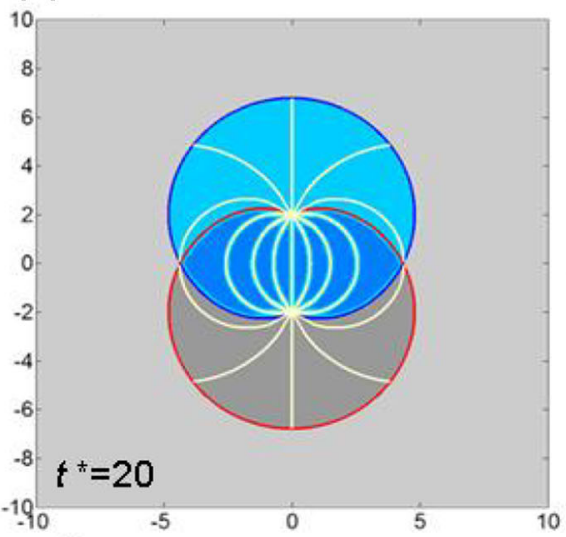

(c)

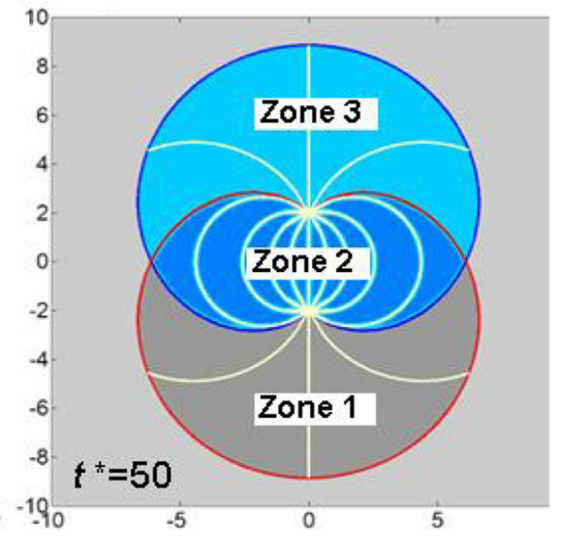

(d)

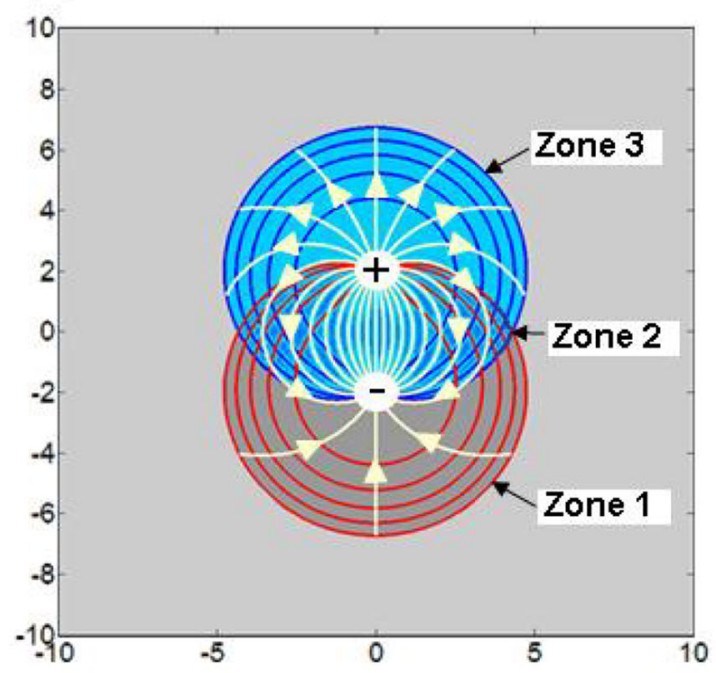

Fig. 3 a-c Doublet made up of distinct injector and producer wells spaced by $d^{*}=4$. Time-series of waterflood-advance and oilwithdrawal contours in balanced doublet. Runtimes are indicated in the lower left corner of each plot. d Red contours oil-withdrawal contours showing expanding outline of region that already contributed oil to the production well. Blue contours flood-advancement contours $\left(m *\right.$ injector $=+1 ; m^{*}$ producer $=-1$, runtime $t^{*}=20$, and contour spacing $\left.t^{*}=4\right)$ 
contours in Fig. 5 track the advancing flood front in time (blue contours) as well as the simultaneous growth of the oil-withdrawal and water drainage front (red contours).

Waterflood advancement in a widely spaced doublet shows that the appearance of water-cut in the production well occurs later when the distance between the injector and producer increases. A practical recommendation, based on our analytical flow visualizations above, is that waterdrive in doublets should never use an injection rate that is higher than the producer rate. The adverse effects of overbalanced water injection are: (1) cusping of the flood early in the field life, (2) water cut increases rapidly due to streamline jetting, (3) only a relatively small area of the oil in the reservoir is moved into the production well, and (4) most oil will be swept away from the producer by the waterflooding (an effect termed 'flood bypass' in our study).

The doublets of Figs. 3 and 4 were volume-balanced, while Fig. 5 was slightly underbalanced. Figure $6 \mathrm{a}-\mathrm{d}$ visualizes the effect of overbalanced flooding in a doublet with a relatively narrowly spaced well pair. The injector is four times as strong as the producer, which retards oil production because the overbalanced water sweep quickly surrounds the production well. Many streamlines guiding the flood water as it moves away from the injector well fully bypass the production well. Clearly, such a sweep will not benefit the producer well. Zone 1 remains small and is quickly overtaken by Zone 2 and encapsulated by Zone 3 flood, which effectively blocks the well from draining any further oil from the reservoir (Fig. 6c). The occurrence of a flow stagnation point (annotated in Fig. 6d) prevents any far-field oil from reaching the producer well, ensuring complete blockage. The producer wells will have a very high water cut already early in the production history. The effects caused by overbalanced waterflooding are precisely counter to what is aimed for in improved oil recovery projects by water injection. We conclude that the overbalanced flooding illustrated in Fig. 6 should be avoided in any case and at all cost. Oil sweep of Zone 1 occupies a very small area and is depleted in an early stage of the flooding. The producer has $100 \%$ water cut after Zone 2 has overtaken Zone 1. As long as doublet continues, Zone 3 will expand and continue pushing water past the producer well, effectively moving more far-field oil further away from the production well.

The potentially adverse effects of overbalanced flooding in doublet development must be mitigated either by balanced or underbalanced injection. To evaluate the best injection strategy, the effect of a relatively slow, underbalanced injection rate was systematically investigated (Fig. 7). A slower rate of injection relative to the producer will increase the area drained by oil-withdrawal contours. At the same time, only a very small area is swept by the underbalanced flood (Fig. 7a, b). However, flood bypass of the producer well cannot occur, as is highlighted by farfield oil replenishment of Zone 1 (Fig. 7a, b). The effect of underbalanced flooding is that Zone 1 remains relatively large and the area effectively flooded (Zones 2,3) cannot expand further due to a finite bulb-shaped flood area, the outer limit of which is indicated by the far-field oil flight path (Fig. 7a, b; black contours).

The size of the flood area is determined by both the relative rate of the well pair and the distance between the injector well and the flow stagnation point. The distance between the flood flow stagnation point and the injector well (which can be determined using Eq. 3) provides a good measure for the maximum width of the waterflood (measured normal to the connector of the well pair, this is (a)

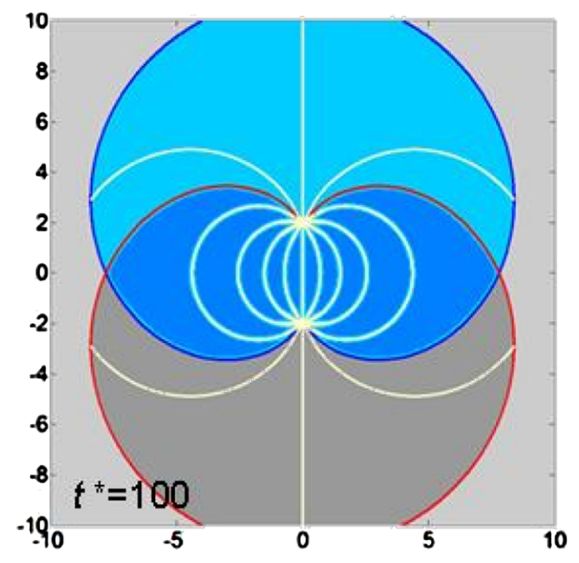

(b)

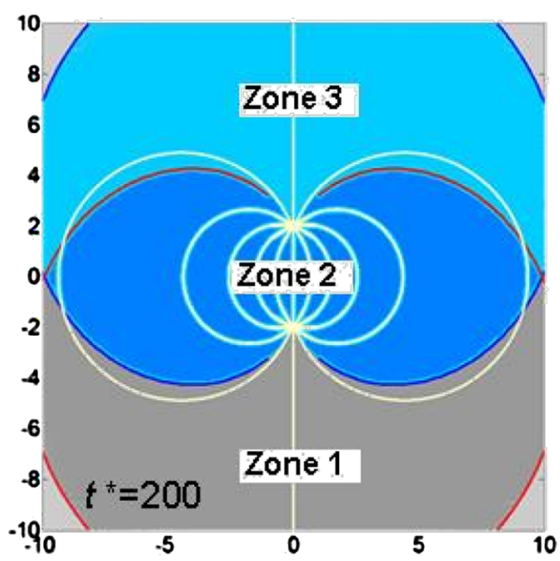

(c)

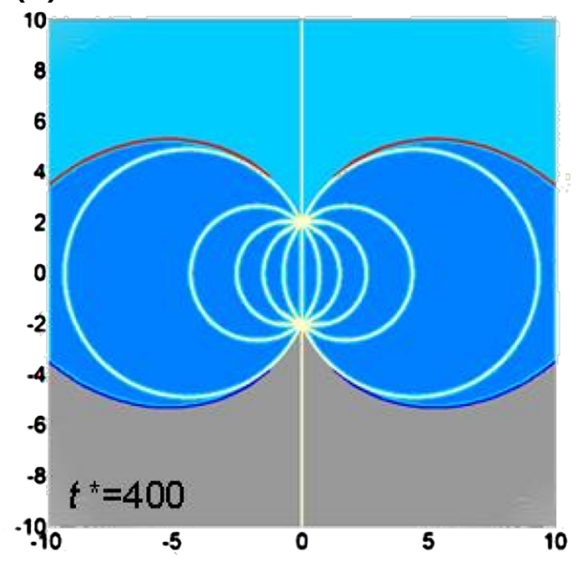

Fig. 4 Continuation of flooding in Fig. 3b, c for doublet made up of distinct injector and producer wells spaced by $d^{*}=4$. Runtimes are indicated in the lower left corner of each plot $\left(m^{*}\right.$ injector $=+1$; $m^{*}$ producer $=-1$ ). Crucially, the region occupied by Zone 2 is the only portion of the reservoir where sweep has passed and brought oil to the producer well. Zone 3 is the reservoir portion flooded (light blue) but water pushed oil further way from the producer rather than toward it 


\section{(a)}

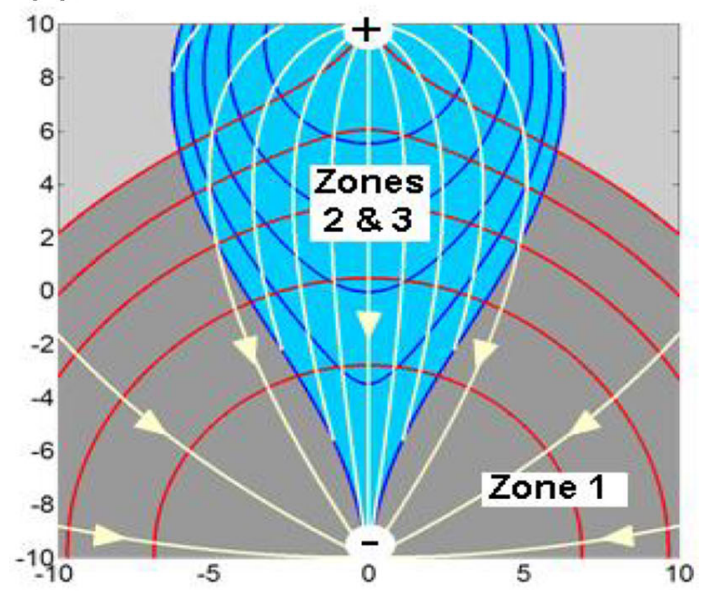

(b)

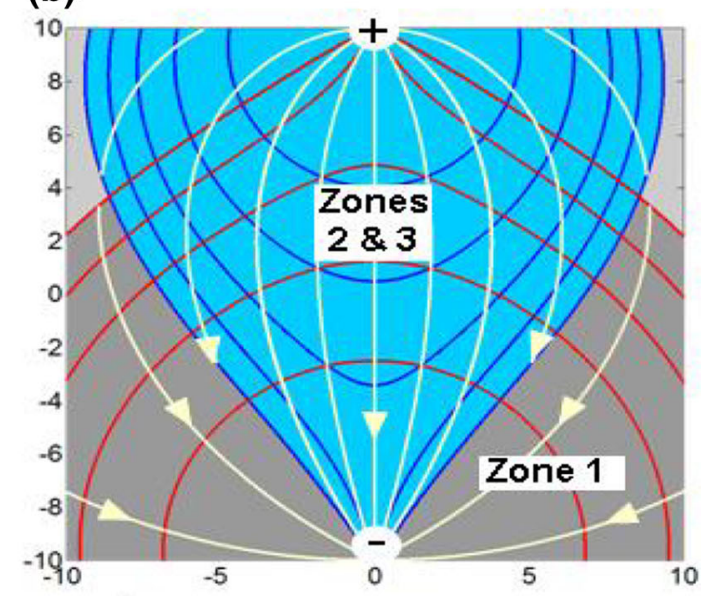

(c)

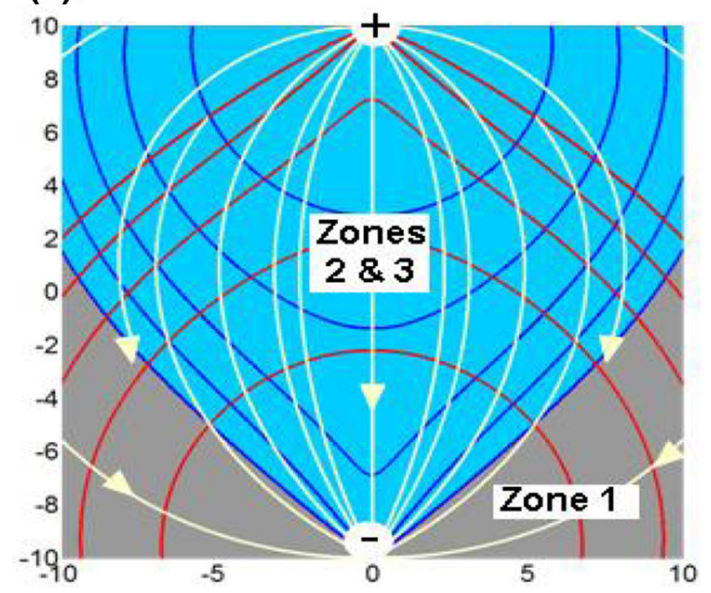

Fig. 5 Underbalanced flooding for widely spaced doublet. Distance between well pair is $\left(d^{*}=20\right)$. Well rates are: a $m^{*}$ injector $=+0.25$; $m^{*}$ producer $=-1 ; \mathbf{b} m^{*}$ injector $=+0.5 ; m^{*}$ producer $=-1 ; \mathbf{c} m^{* \text { in- }}$ jector $=+0.75 ; m^{*}$ producer $=-1$. Runtime for all cases is $t^{*}=125$, and contour spacing $t^{*}=25$

about twice the stagnation point separation with the injector). Zone 1 drains a large reservoir area, but the flood advancement of Zones 2 and 3 is confined to a very limited section of the reservoir. Floodwater cannot cross the farfield flow lines and remains confined to an oval region between the stagnation point and the producer well; the width of the water sweep is limited by, and related to, the stagnation point distance to the injector [see Eq. (3)]. The areal width effectively swept by the floodwater grows when the rate of the injector becomes closer to that of the producer. Eventually, well rates may be become balanced again, which is analyzed in Figs. 3 and 4.

\section{Doublets in discontinuous reservoir}

The doublet arrangements studied in Figs. 2, 3, 4, 5, 6 and 7 assumed homogeneous reservoirs devoid of any discontinuities (no faults). Faults—even major ones-are easily overlooked in the early phases of reservoir exploration and development. The effect of an unrecognized, impermeable fault blocking doublet flow was also systematically investigated in our study. Obviously, the critical parameters [cf., Eq. (2)] are fault mid-point $\left(z_{f}\right)$, orientation (angle $\left.\beta\right)$ and total length $(2 l)$.

Figure 8a-d shows a time-series for a balanced doublet-but with flow space obstructed by an impermeable fault. The presence of the fault results in the development of two separate sections in the reservoir occupied by Zone 2 (Fig. 8c). Once the flood has fully engulfed the fault surface, the obstruction no longer plays any significant role for the oil sweep efficiency (Fig. 8d). At an advanced stage of flooding, the doublet in the faulted reservoir develops as a regular balanced doublet. However, the time-of-flight for the water flood sector in the left-hand side of the image of Fig. 8 is much faster than for the right-hand-side sector.

Figure 9a-c shows how a 'sweep shadow' (term coined here) occurs when the flood is deflected by an impermeable fault zone. The fault was placed half-way the connector of the doublet's well pair with its mid-point crossing the origin, so that the flow discontinuity affects the entire flow space of the doublet. The presence of the fault delays the arrival of the floodwater in the producer well (compare Figs. 9a, 5a).

In the next set of simulations, the fault plane was located in one half of the doublet flow space (Fig. 10). The result is that the sweep shadow affects only one half of the doublet. A fault barrier that predominantly occupies only one half of the doublet space barely affects the waterflood path of the other half of the flow space (compare Figs. 2c, 10b). However, cusping in the doublet space not shielded from the flood by the fault's sweep shadow (Fig. 10a) occurs faster than when the fault would be absent (situation of Fig. 2b). Reducing the rate of the producer well by tightening the wellhead diameter in an attempt to reduce the water cut and mitigate cusping is not an effective remedy (Fig. 10b). The water front still cusps, and water breakthrough still occurs fast due to streamline jetting around the fault tip. 
Fig. 6 Time-series of waterflood advance and oil withdrawal in an overbalanced doublet (wells separated by $\left.d^{*}=4\right)$. Injection well rate $(m *$ injector $=+4)$ is four times as strong as the production rate $\left(m^{*}\right.$ producer $\left.=-1\right)$. a-

d Runtime $t^{*}=1,2,4$ and 20, respectively. Spacing of time contours in (d) is $t^{*}=4$

\section{(a)}

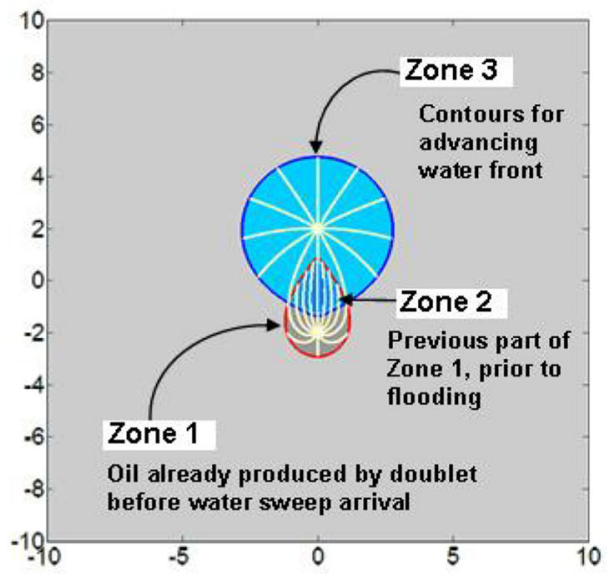

(c)

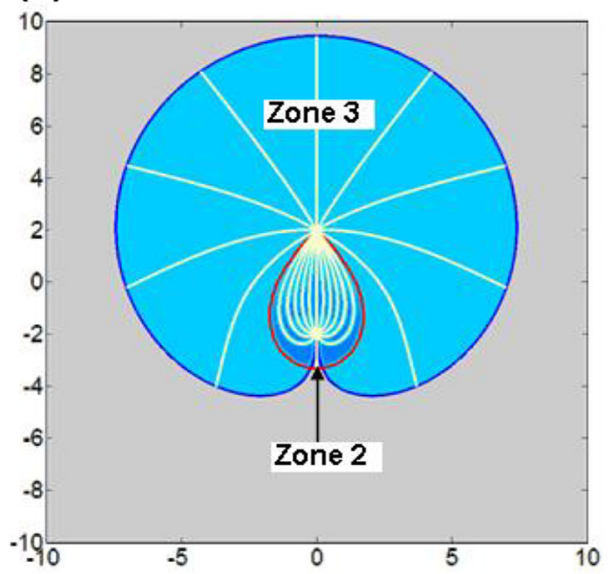

(b)

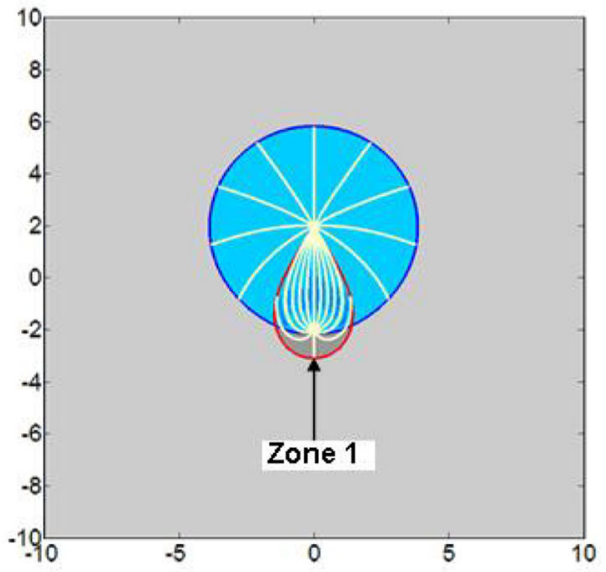

(d)

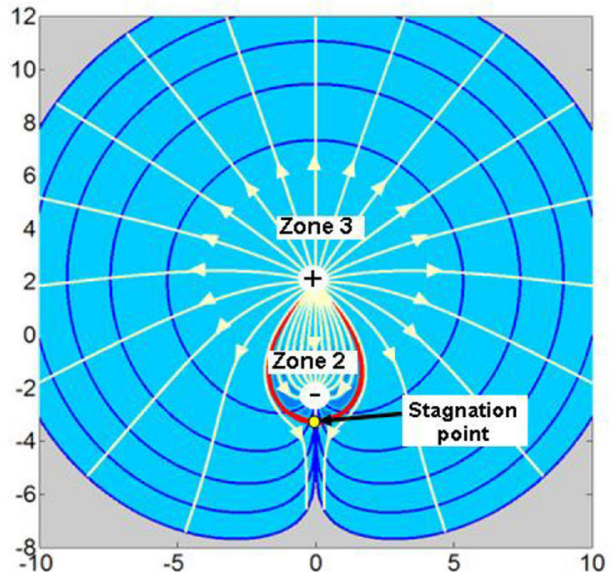

(a)

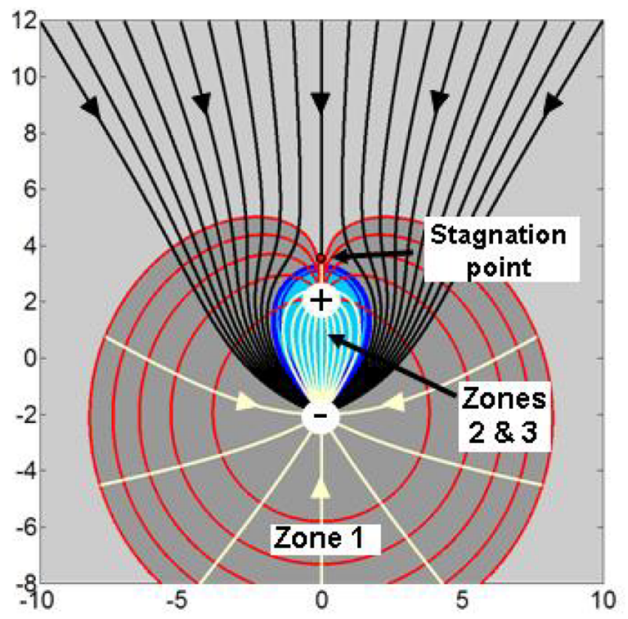

Fig. 7 Limited flood region due to flow stagnation points close to injector as a result of doublet's injection well rate being relatively small. Stagnation point distance to injector varies with the relative strength of the well pair. a Stagnation point located at $0+31 /$ $3 i \quad\left(m *\right.$ injector $=+0.25 ; m^{*}$ producer $=-1$, runtime $t^{*}=40$, and contour spacing $\left.t^{*}=8\right)$; b Stagnation point located at $0+6 i(m *$ injector $=+0.5 ; \quad m^{*}$ producer $=-1$, runtime $t^{*}=40$, and contour (b)

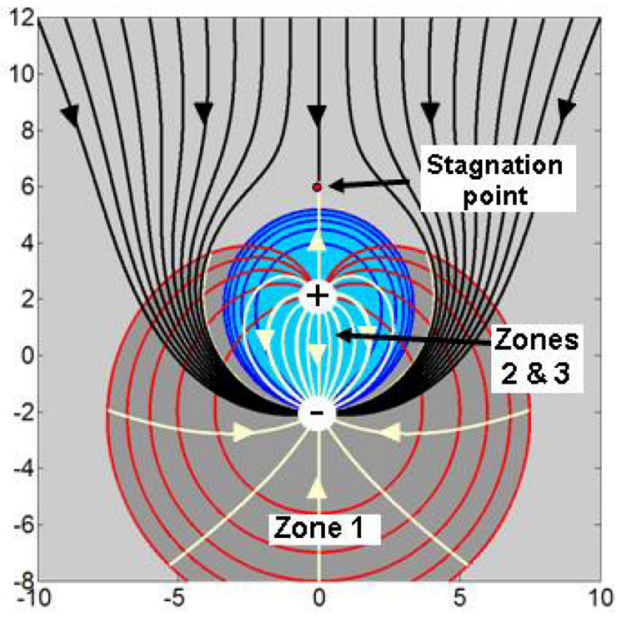

spacing $t^{*}=8$ ). Black contours are flow lines for far-field oil replenishment of Zone 1. Travel time was extended for these far-field flight paths and for water flood of Zones 2 and 3. Waterflood cannot expand beyond the stagnation point occurring above it. The stagnation point moves away from the injector well when the ratio of the absolute rates for injector and producer well rates becomes larger 
Fig. 8 Time-series of waterflood advance and oil withdrawal in a balanced doublet (wells separated by $\left.d^{*}=20\right)$ affected by an impermeable fault. a-c Runtime $t^{*}=25,75$, and 125 , respectively. Case (d) is identical to (c) but now includes contours of all previous time steps $(m *$ injector $=+1$; $m^{*}$ producer $=-1$, and contour spacing $t^{*}=25$ ) (a)

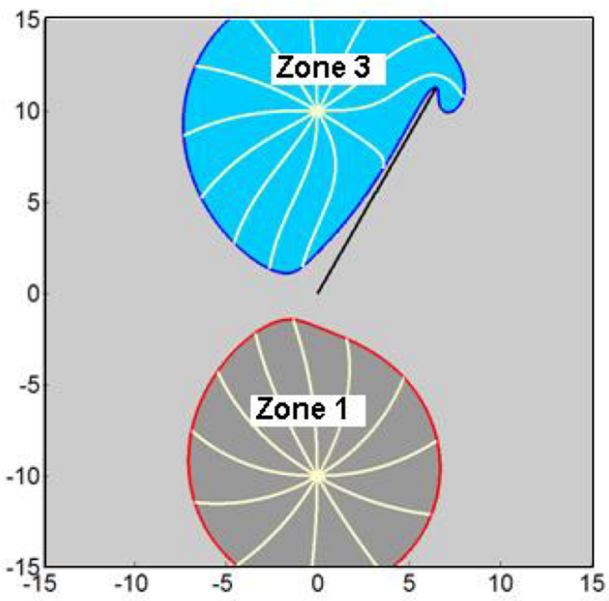

(c)

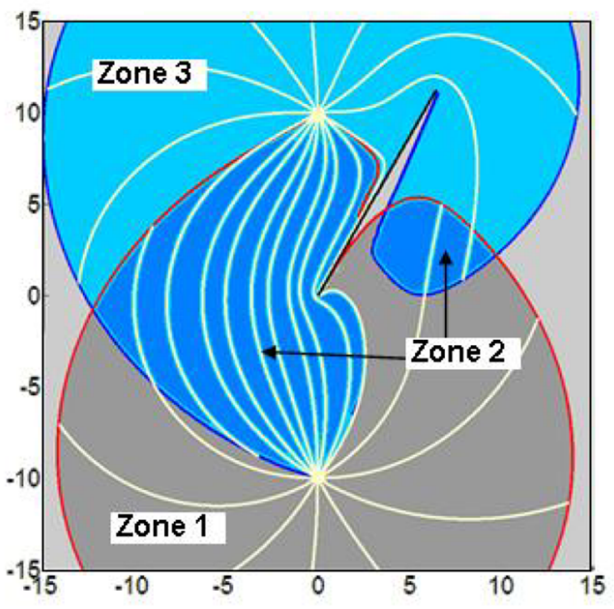

(b)

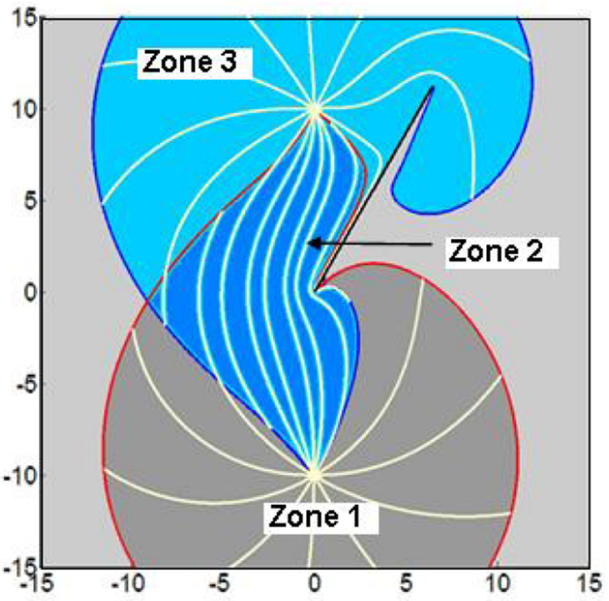

(d)

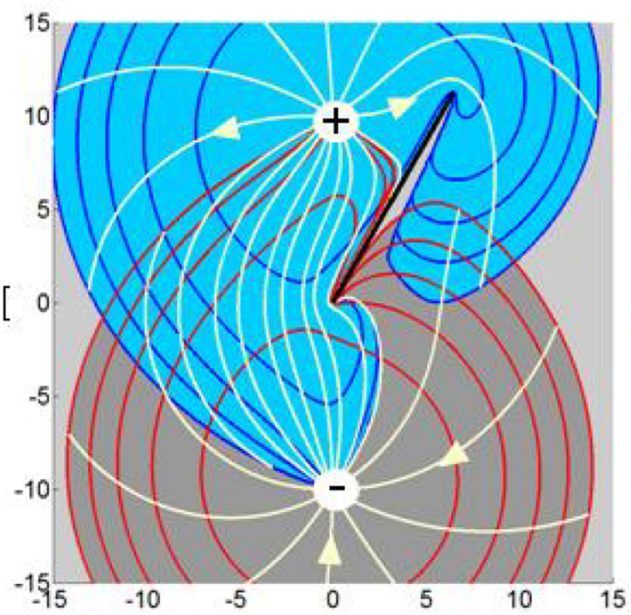

Excessive water cut in a doublet flow cell intersected by a fault can be delayed by a reduction of the injection rate (Fig. 10c). The flood front then advances slower and with narrower streamtubes; only a narrow region is effectively swept by the flood. None of the floodwater sweeps past the producer well (Fig. 10c). The presence of the fault results in the development of two separate sections of the reservoir occupied by Zone 2 .

The principal sub-conclusions of this section are that usage of slow flooding rates in faulted reservoirs is an effective mitigation (1) against growth of flood shadows and (2) against flood bypass of the producer well.

\section{Model results for 7-spot well patterns}

\section{Single 7-spot well pattern (continuous)}

The next set of flood simulations focuses on more complex well patterns. The 7-spot has the largest degree of radial symmetry within the common suite of regular drilling patterns (line drive, 9-, 7- or 5-spot). We preferred the 7-spot well pattern because it allows a comparison with the classical blotting-paper electrolytic models of Wyckoff et al. (1933). Several flooding scenarios are possible for the 7-spot pattern. A systematic series of runs for a single 7-spot cell (one injector, six producers; Fig. 11a) reveals that the shape of the flood front is critically dependent on the relative rates of the injector and producer wells.

Scenario I assumes no water injection occurs; the corresponding oil-withdrawal contours are shown in Fig. 11b (Row I). Oil already drained is outlined (dark-gray shaded, red contours). Oil-withdrawal contours look like a nested set of fans broadening outward. Streamlines are highlighted in yellow. New far-field oil has moved into the contoured space and will be produced when the runtime is extended, unless blocked by the flood. A first observation of Fig. 11b (Row I) is that producing wells do not withdraw oil as concentric bubbles. Instead, the streamlines of each well 
(a)

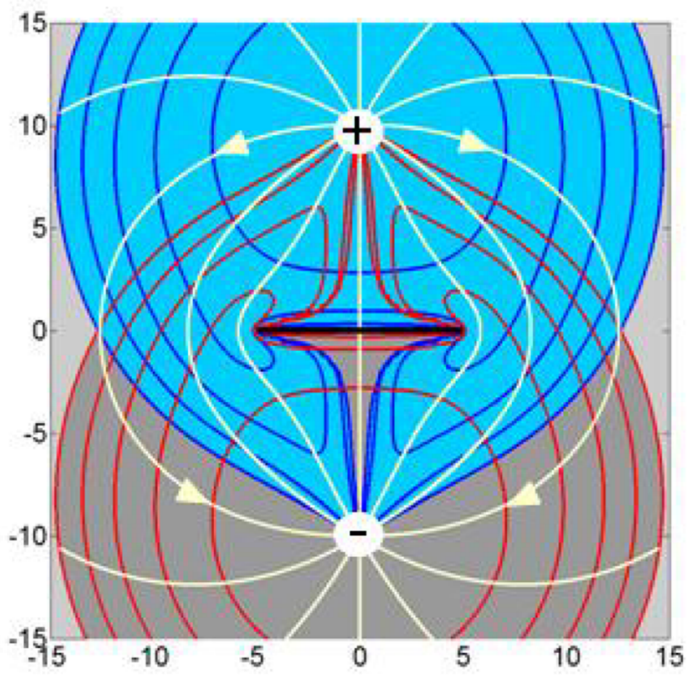

(b)

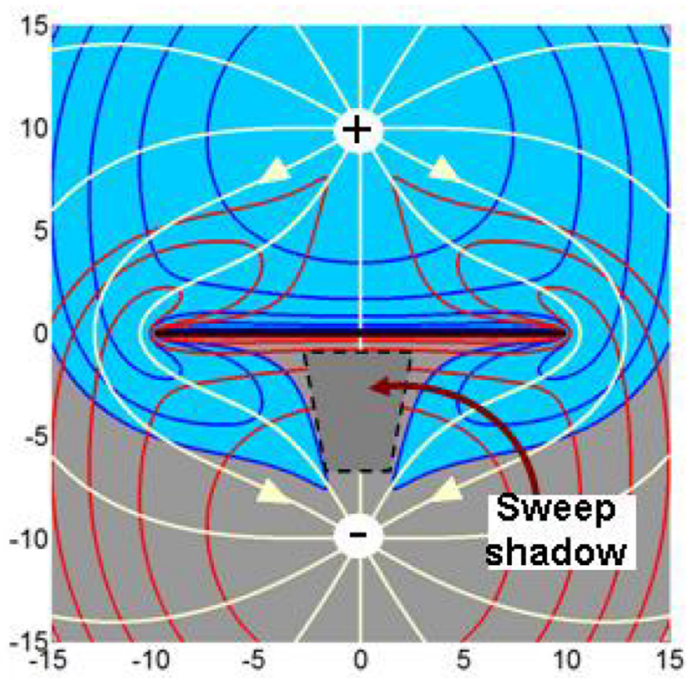

(c)

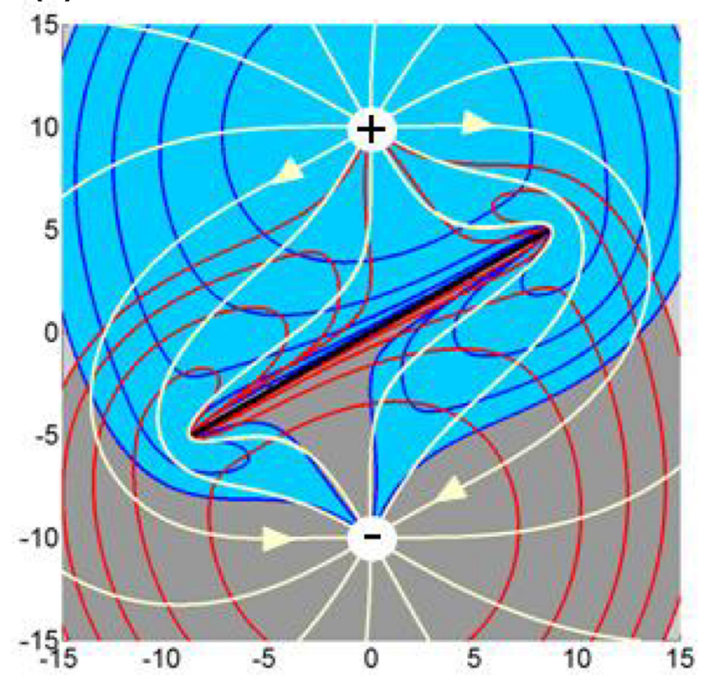

4Fig. 9 Waterflood deflection in doublet flow of balanced well pair obstructed by an impermeable fault. Well spacing $d^{*}=20$ in all cases. Fault length in a $2 l^{*}=10$ and $\mathbf{b} 2 l^{*}=20$, both perfectly horizontal; and (c) $2 l^{*}=20$, with fault inclined at $60^{\circ}$ to the connector of the injection and producer wells. Region of sweep shadow is largest when the fault length is larger and angle with doublet well connector is maximum (i.e., $90^{\circ}$ ). Further parameter settings are $m^{*}$ injector $=+1 ; m^{*}$ producer $=-1$, runtime $t^{*}=20$, and contour spacing $t^{*}=4$

are affected by the presence of all other wells. A second observation is that a central area of stranded oil develops between the producer wells; this oil will not be recovered as long as all wells are flowing (equal rates are used in this run).

Scenario II assumes production and injection wells have similar, underbalanced flow rates; the classical flood pattern develops (resembling a spider-web pattern; Fig. 11a, Row II). The sweep space is contoured with isochrons (dark blue) of successive water advancement. Flood is light blue and sweep isochrons have time spacing $t^{*}=1$. Figure 12 shows the corresponding images of the analog laboratory visualization by Wyckoff et al. (1933). We can immediately conclude that Fig. 12 is not a universal solution for a 7 -spot flooding, but represents only one specific case of underbalanced well rates. The required conditions are specified in the caption of our Fig. 11 (Row II).

Scenario III uses an increased rate for the central injection well toward a better balance (but still underbalanced) with the six producer wells. Now the central region is fully swept by the flood and less or no stranded oil occurs (Fig. 11a, Row III). Scenario IV is for perfect balancing; the flooding pattern changes from a spider-web pattern (Fig. 11a, Row II) via the intermediate case (Row III) to a flower pattern (Row IV). When water injection occurs, the oil-withdrawal patterns resemble chestnut-tree leaves (Fig. 11b, Rows II-IV).

Balanced well rates (Fig. 11, Row IV) are most suitable for serial well pattern roll-out (see Appendix). However, underbalanced producers (Fig. 11, Rows II, III) withdraw oil from larger areas of the reservoir quite effectively. Also, the balanced well pattern (Fig. 11, Row IV) quickly over-floods the region beyond the producing wells, which is why the effective oil-withdrawal area is much smaller than in the underbalanced flooding scenarios of Fig. 9a (Rows II, III). We conclude that slow, underbalanced flooding can be more effective than balanced and overbalanced flooding-schedules. The higher recovery factors are realized by balanced and underbalanced flooding, depending on the properties of the oil. 


\section{(a) Balanced Floodina}
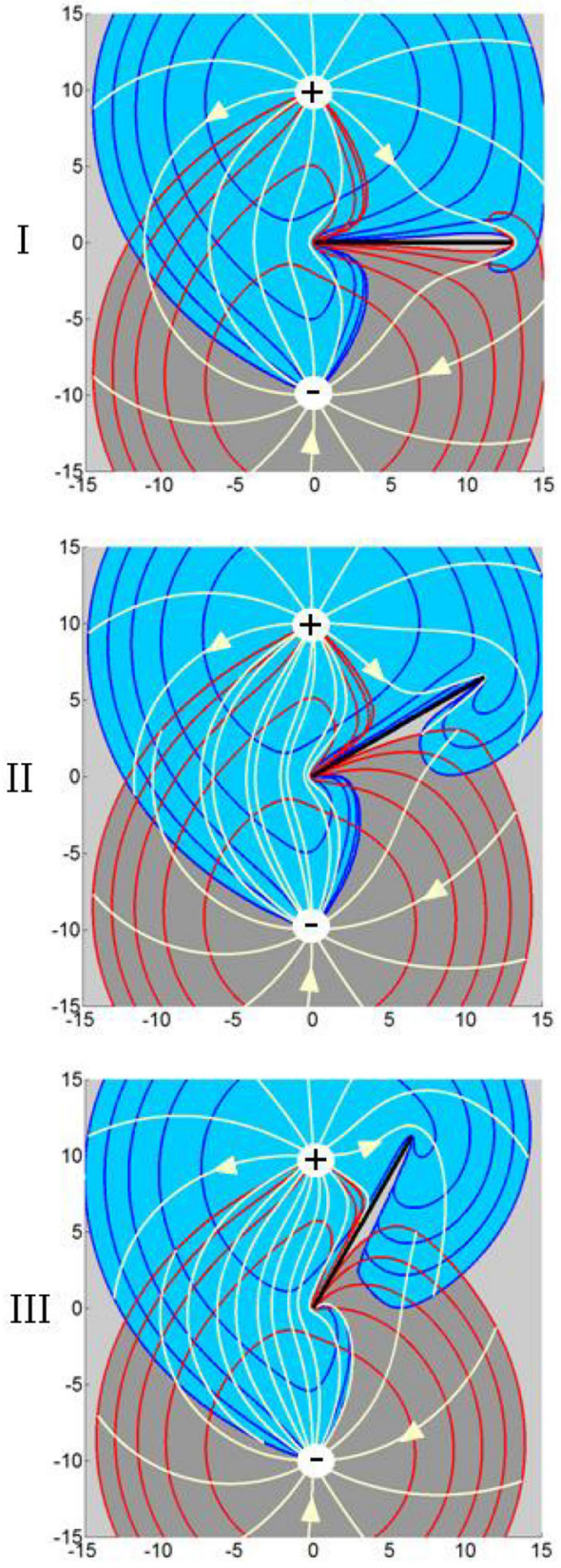

\section{(b) Overbalanced}
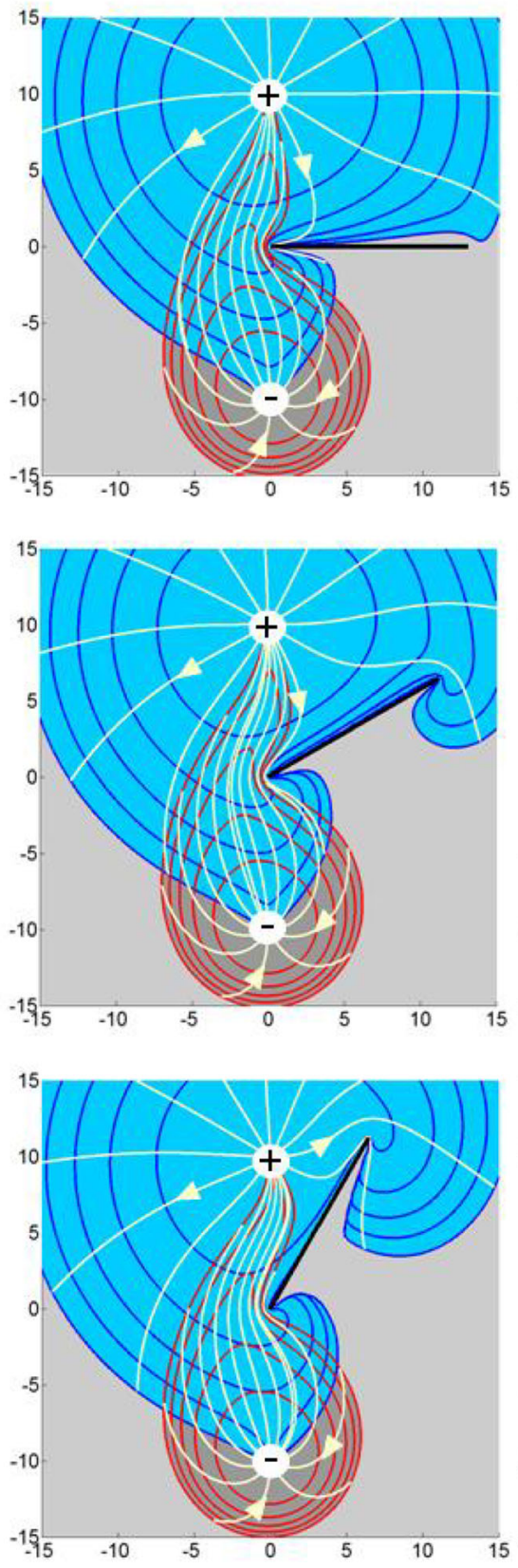

\section{(c) Underbalanced}
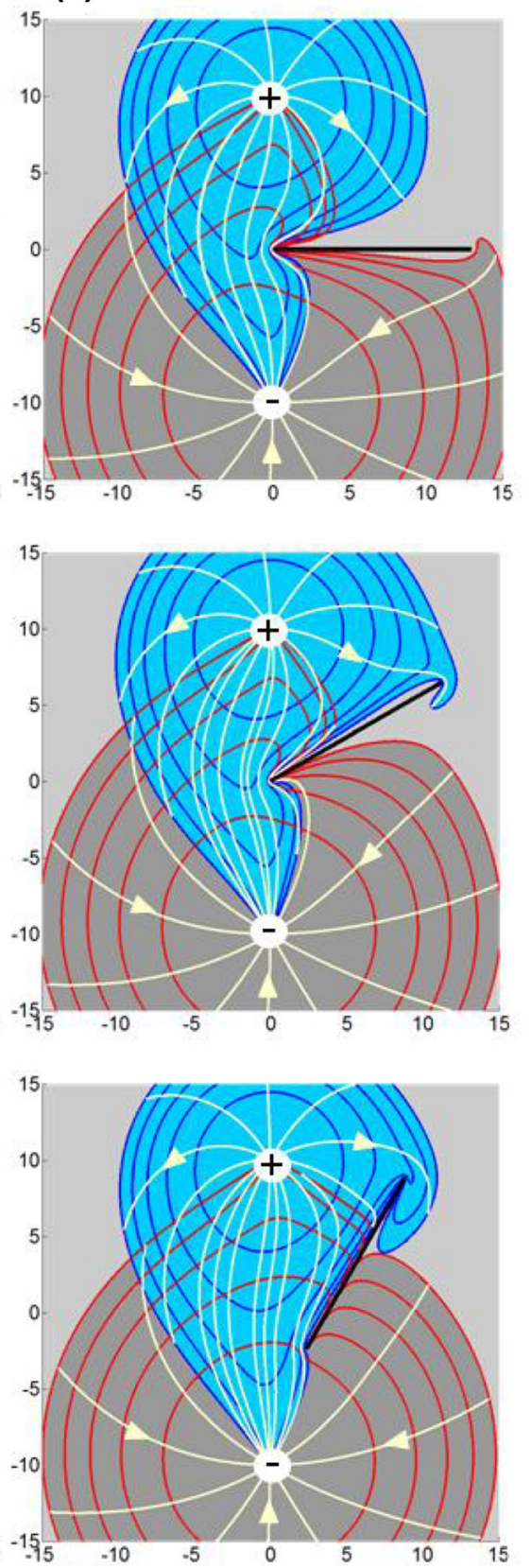

Fig. 10 Waterfloods affected by impermeable fault located in one half of the doublet flow space. Progressive oil-withdrawal of faulted oil reservoir with: a mathematically balanced well rates for injector and producer $\left(m^{*}\right.$ injector $=+1 ; \quad m^{*}$ producer $=-1, \quad$ runtime $t^{*}=125$, contour spacing $\left.t^{*}=25 ; d^{*}=20\right)$, b Overbalanced rates $\left(m *\right.$ injector $=+1 ; m^{*}$ producer $=-0.25$, runtime $t^{*}=125$, contour

\section{Fractured single 7-spot well pattern (discontinuous reservoirs)}

We next examine the effect of impermeable faults on the sweep efficiency of a single 7-spot (Fig. 13a). A fault blocking the flooding front will result in premature water spacing $\left.t^{*}=25 ; d^{*}=20\right)$, and c Underbalanced rates ( $m *$ injector $=+0.5 ; m^{*}$ producer $=-1$, runtime $t^{*}=125$, contour spacing $t^{*}=25 ; d^{*}=20$ ) Fault has non-dimensional length $2 l^{*}=13$ for all cases, and left-tip of fault starts in the origin; fault orientations are I $90^{\circ}$, II $60^{\circ}$ and III $30^{\circ}$

breakthrough for the four producer wells receiving all the injection water; these wells are effectively overbalanced by the flood. Consequently, only a fraction of the oil will be produced by these wells (Fig. 13b). In contrast, wells that are shielded from the waterflood by the fault are flooded in underbalanced fashion. Each of the two shielded wells will 
Fig. 11 Single 7-spot well pattern with central injector. a Advancing flood (yellow stream lines; dark blue contours for flood advance). b Oilwithdrawal contours (red) and stream lines (yellow). Rows I$I V$ show flood-advance patterns (column a) and oil-withdrawal contours (column b) critically depend on the relative rates of the injector and producer wells. Runtime for all cases is $t^{*}=10$ and spacing of isochrons is $t^{*}=1$. Row I: no water injection $(m *$ injector $=0$; $m^{*}$ producer $\left.=-1\right)$; Row II Underbalanced injection $(m *$ injector $=+1$; $m^{*}$ producer $=-1$ ); Row III Underbalanced injection $(m *$ injector $=+3$; $m$ *producer $=-1) ;$ Row IV Balanced injection $(m *$ injector $=+6$; $m$ *producer $=-1)$ (a) Water flood
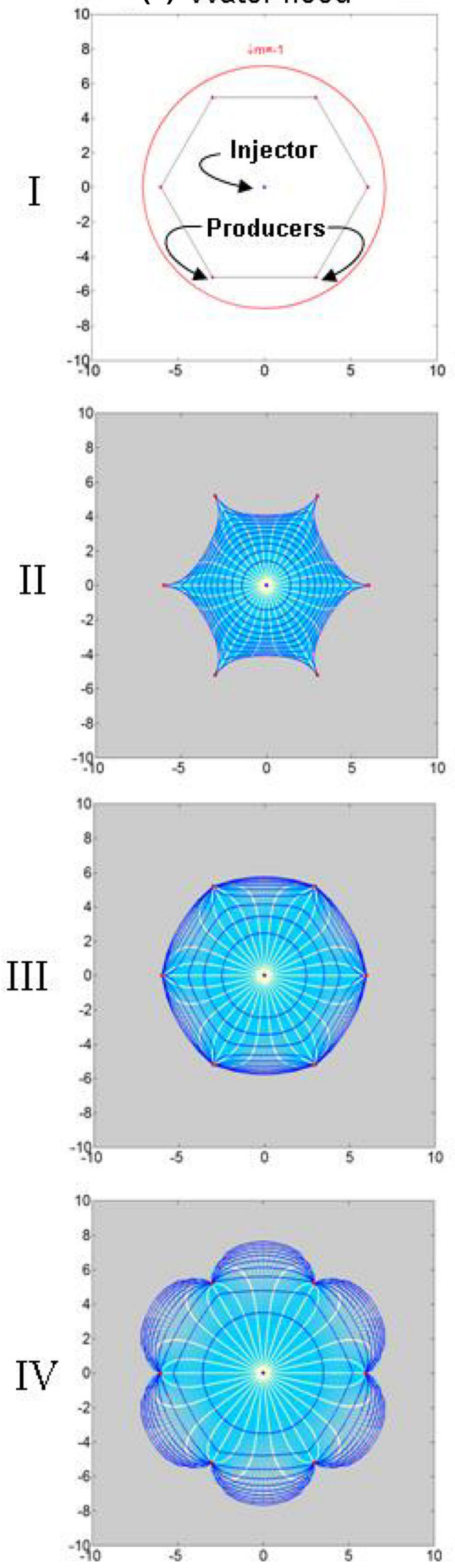

(b) Production
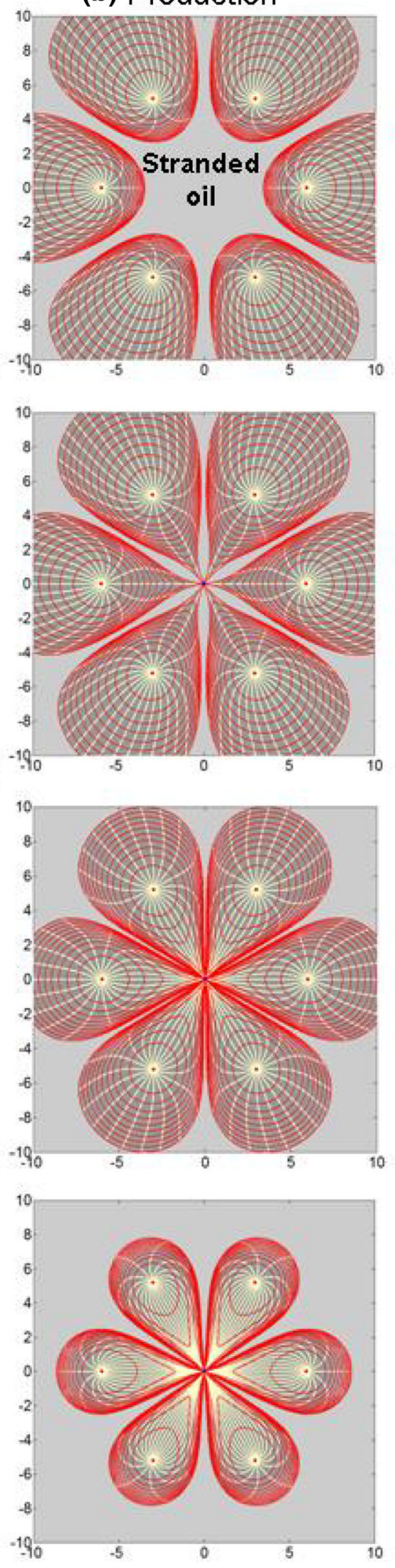

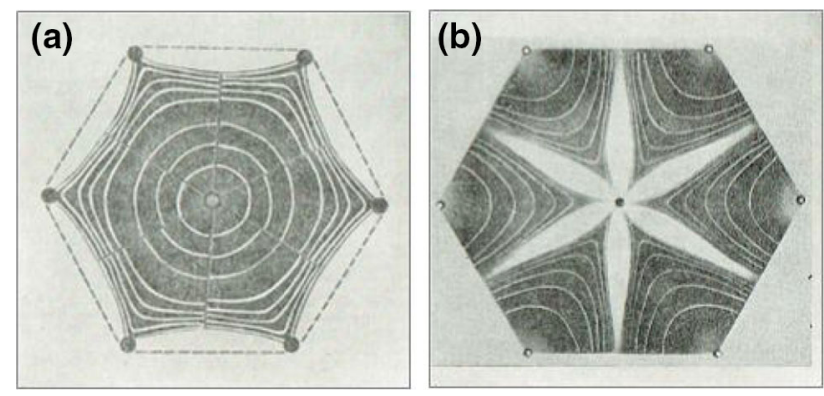

Fig. 12 Simulation of advancing flood in single 7-spot well patterns by Wyckoff et al. (1933). a Central injector and peripheral producers shows advancing flood as dark blotting in electrolytic experiment. b Reversal of injectors and producers shows pattern corresponding to oil-withdrawal contours imaged more completely in our Fig. 11b, Row II

produce three or four times as much oil as the prematurely flooded wells across from the fault. Scenarios I and II in Fig. 13 differ in fault lengths and orientation. In spite of the much longer fault in Scenario II, oil-withdrawal contours of Scenarios I and II are quite similar (compare Rows I and II in Fig. 13b).
The effects of different fault lengths and orientations on the oil-withdrawal pattern were modeled for intermediate fault lengths. The results are separately visualized in Fig. 14a-d.

\section{Arbitrary producer well patterns, infill drilling and peripheral flooding}

Reservoir geology may require deviation from field development with a regular drilling pattern. Alternatively, surface access may be too limited to allow a regular drilling pattern. This section presents oil-withdrawal patterns for field development with arbitrary well patterns. Floods applied in newer offshore, deep water fields are rarely drilled in any sort of regular pattern, and there is no steady state. Flood models developed with high-fidelity FD simulations are the industry norm. However, because of the high/risk reward characteristics of nearly all principal types of fields (legacy field, new field, green fields), benchmarking of streamlines with closed-form solutions may provide fast and useful support to such efforts.
Fig. 13 Waterflooding (a) and oil-withdrawal contours (b) for single 7-spot well pattern with central injector obstructed by a fault. Row I Horizontal fault of limited length $\left(2 l^{*}=6\right)$. Row II Oblique fault of much lengthier dimension than field of view $\left(2 l^{*}=200\right)$. Simulation is for mathematically balanced 7 -spot $(m *$ injector $=+6$; $m *$ producer $=-1$, runtime $t^{*}=10$, contour spacing $\left.t^{*}=1\right)$ (a) Water flood
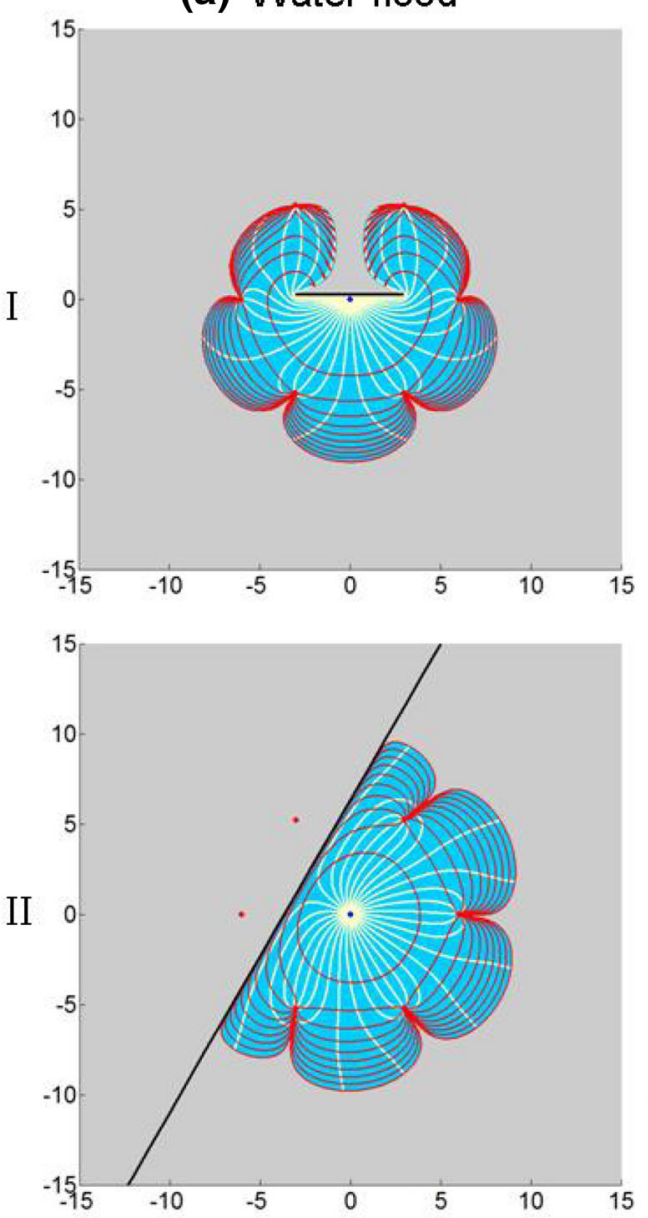

(b) Production
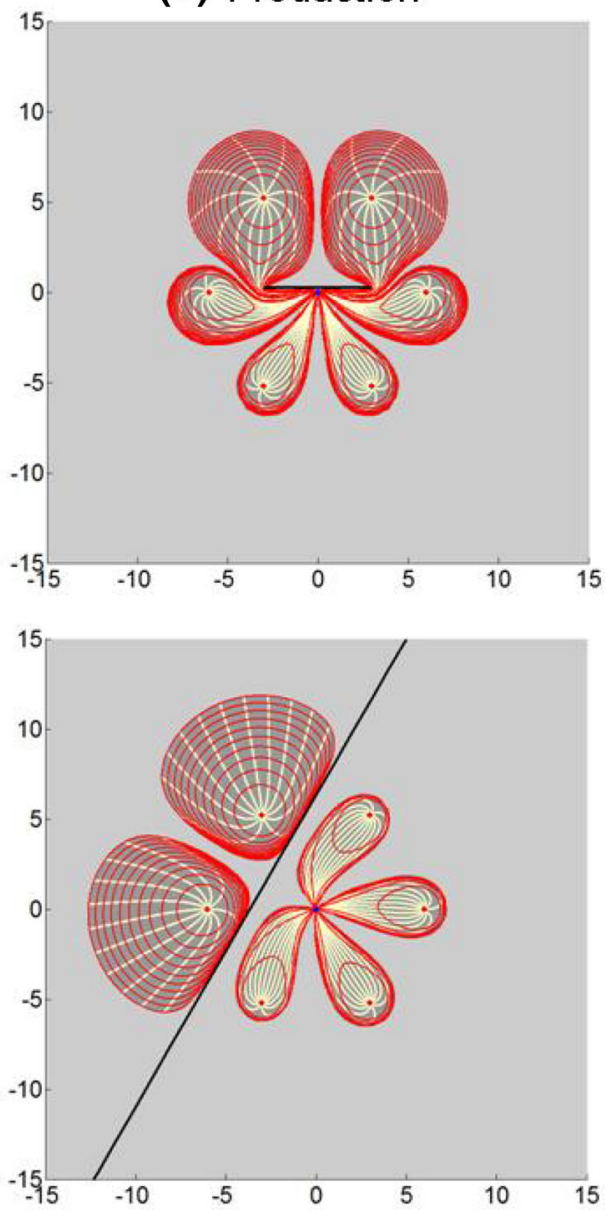
Fig. 14 Effect of variable fault lengths and orientation on oilwithdrawal pattern. Images show oil-withdrawal contours (red) for single 7-spot well pattern with central injector rate $(m *$ injector $=+6)$

mathematically balanced by producer rates

$\left(m^{*}\right.$ producer $\left.=-1\right)$. The faults partially obstruct the waterflood from the central injector, physically upsetting the mathematical mass-balance.

Fault dimensions are

a $2 l^{*}=10, \mathbf{b} 2 l^{*}=13$,

c $2 l^{*}=13$, and $\mathbf{d} 2 l^{*}=20$.

Stream lines are highlighted in yellow. Black oil reservoir is light gray. Oil-withdrawal contours spacing $t^{*}=1$ and total run time $t^{*}=10$ (a)

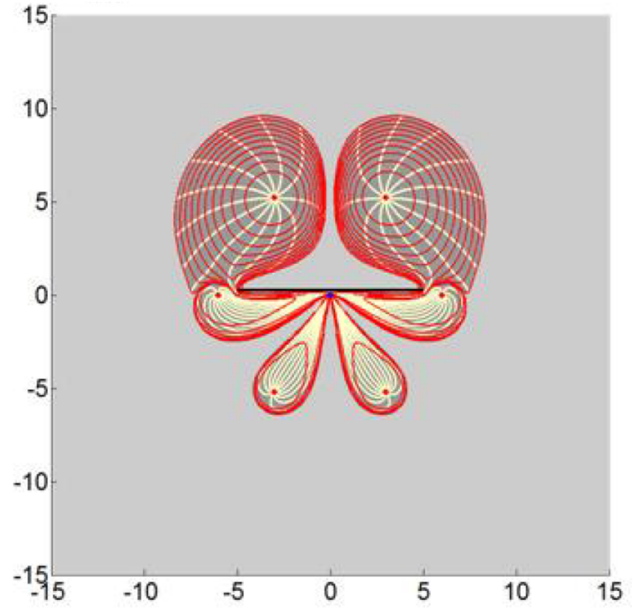

(c)

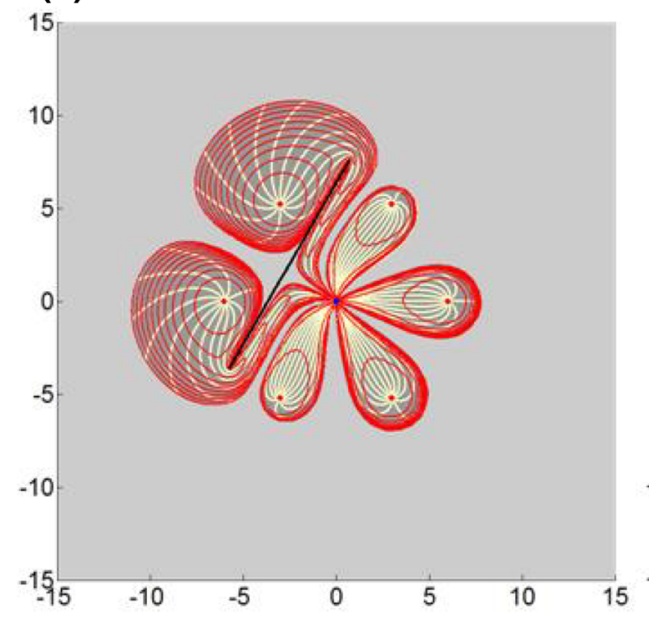

(b)

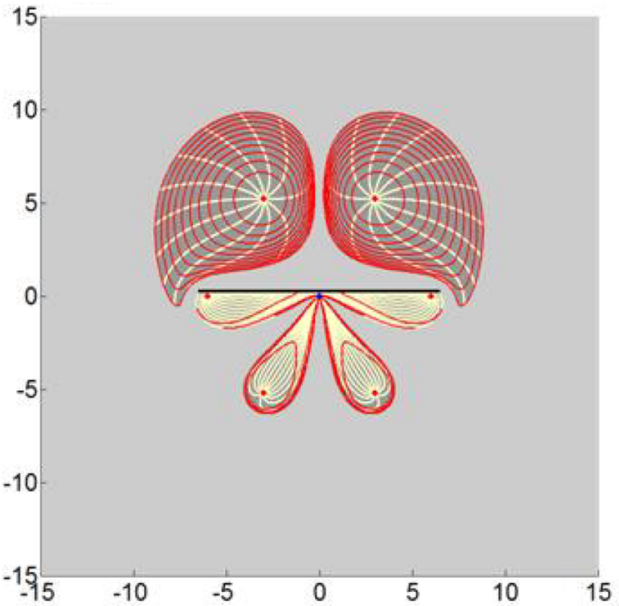

(d)

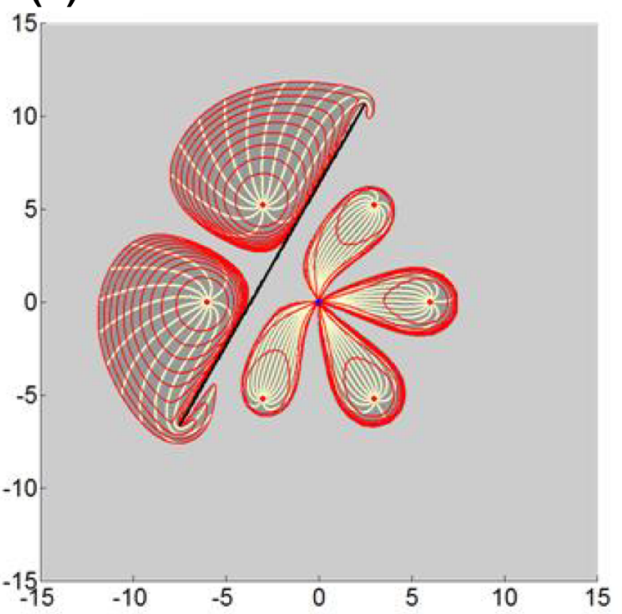

Figure 15 shows the progressive evacuation of oil from a reservoir developed with a random pattern of 14 producer wells; no injection wells occur. Given enough time, the wells will deplete a circular region occupied by the well cluster (Fig. 15f). No stranded oil occurs in the center, unlike that of a case illustrated in Appendix, where a 7-spot cell typically shows stranded oil if no central flood is applied (Fig. 19b, Row I). The reason for no stranded oil in the well pattern of Fig. 15 is that a producer is located in the very core of the well cluster, which thus drains the central reservoir section.

The effect of infill drilling is separately visualized in the synthetic model of Fig. 16. Al-Najem et al. (2012) alleged that analytical solutions could not account for changing well conditions such as infill wells. Such assertions are incorrect, as illustrated by our example of infill drilling (Fig. 16). Wells are drilled in four distinct episodes and immediately begin to produce at, respectively $t^{*}=0,1,2$ and 3. Streamlines will only remain fixed over time indeed when well architecture, number and rates remain constant.
Consequently, the final oil-withdrawal pattern of Fig. 16 differs in details from that shown in Fig. 15f.

A final set of experiments shows the same cluster of producer wells used in Figs. 15 and 16, but now with peripheral water injection wells (Fig. 17a-c). The effect is that the areal expansion of the mullion-shaped oil-withdrawal pattern outlined by the red contours (which all are in oil-producing Zone 1) is halted by the advancing front of the flood (Fig. 17c). Far-field oil can no longer reach the producer wells due to the flooding by peripheral wells. Moreover, any far-field oil will be pushed outward and moves further away from the producer wells.

\section{Discussion}

\section{Common uses and challenges in waterflooding}

Waterflooding has been used as a secondary oil recovery method for over a century to produce numerous oil fields 
Fig. 15 Time-series showing snapshots of expanding oilwithdrawal for random producer wells, without any support from injection wells for flooding. Particle paths are traced by the yellow curves. Red curves show the expanding drainage regions as non-dimensional time contours with spacing $t^{*}=0.5$. The speed of fluid particles is determined by the initial flux strength of each producer (all fixed at non-dimensional strength $m^{*}=-1$ over the total runtime $t^{*}=3$ ) and the relative position of the sources.

Runtimes shown are:

$\mathbf{a} t^{*}=0.5, \mathbf{b} t^{*}=1$,

$\mathbf{c} t^{*}=1.5, \mathbf{d} t^{*}=2, \mathbf{e} t^{*}=2.5$

and $\mathbf{f} t^{*}=3$ (a)

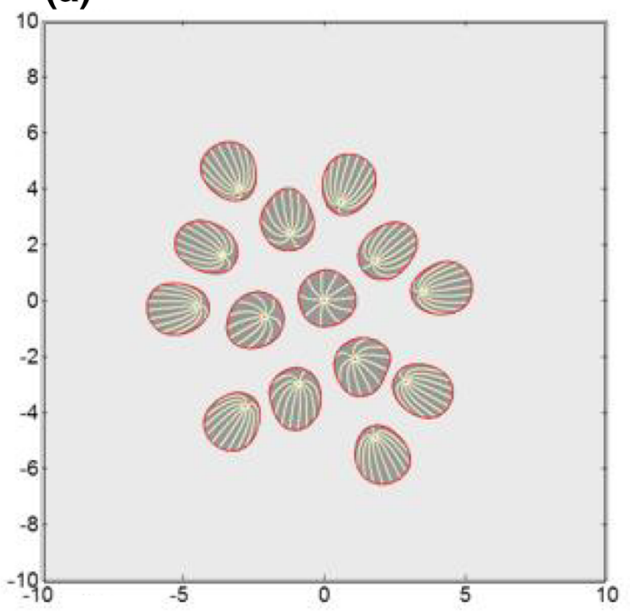

(b)
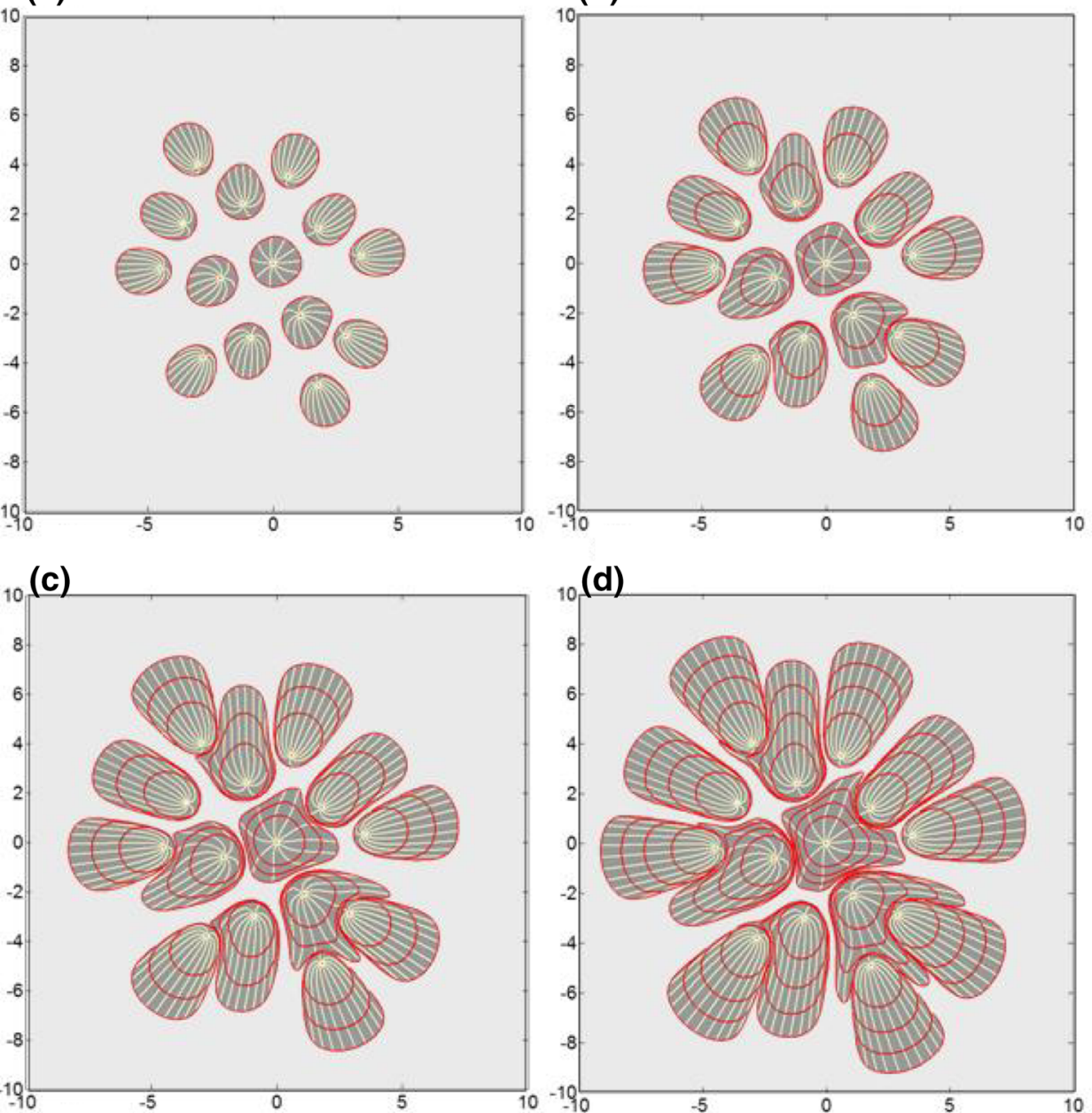

(e)

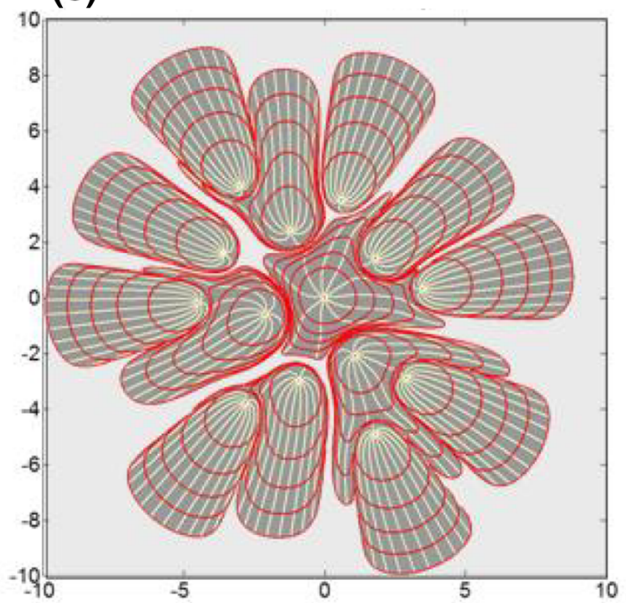

${ }_{10}(d)$

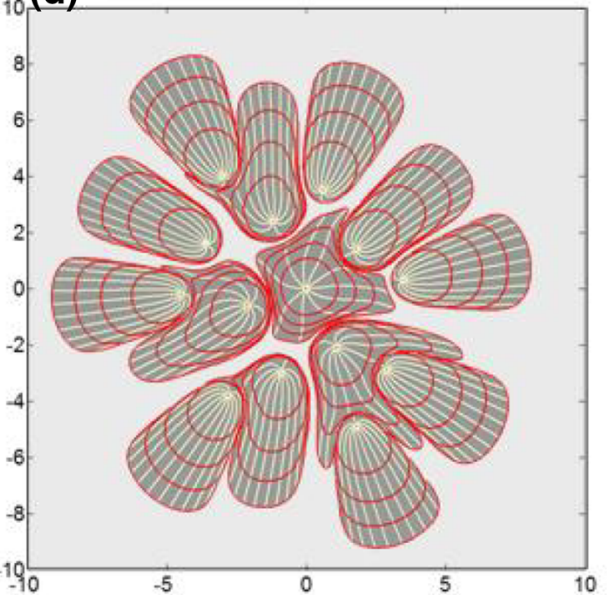

(f)

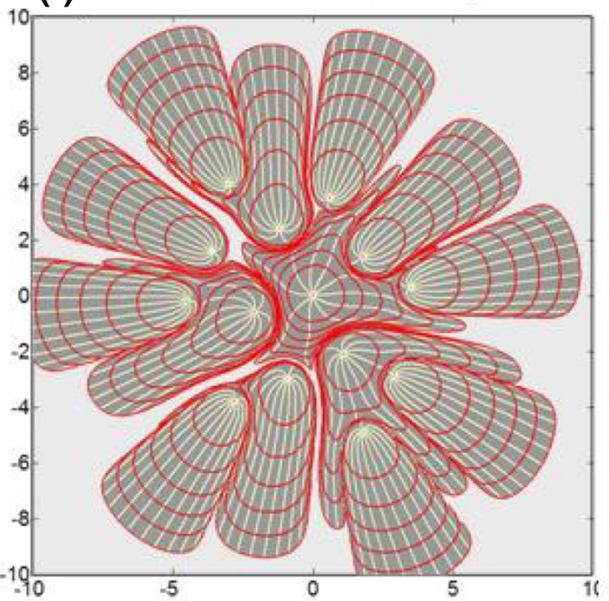

ranging from small to giant fields (e.g., Craig 1970; Willhite 1986; Lake 1989; Towler 2002; Lake and Holstein 2007). To inject water into the reservoir, separate wells are drilled in addition to the wells used to produce oil. The objective of water injection is to enhance oil recovery by sweeping the pore space with water so oil is displaced more effectively toward the producing wells. Water injection also mitigates pressure decline in the reservoir and thus contributes to prolong the fluid flux into the producing well. Some of the world's largest oil fields are produced using waterflooding: Ekofisk (North Sea), Wilmington Oil Field (California), Kuparuk River field (Alaska North 

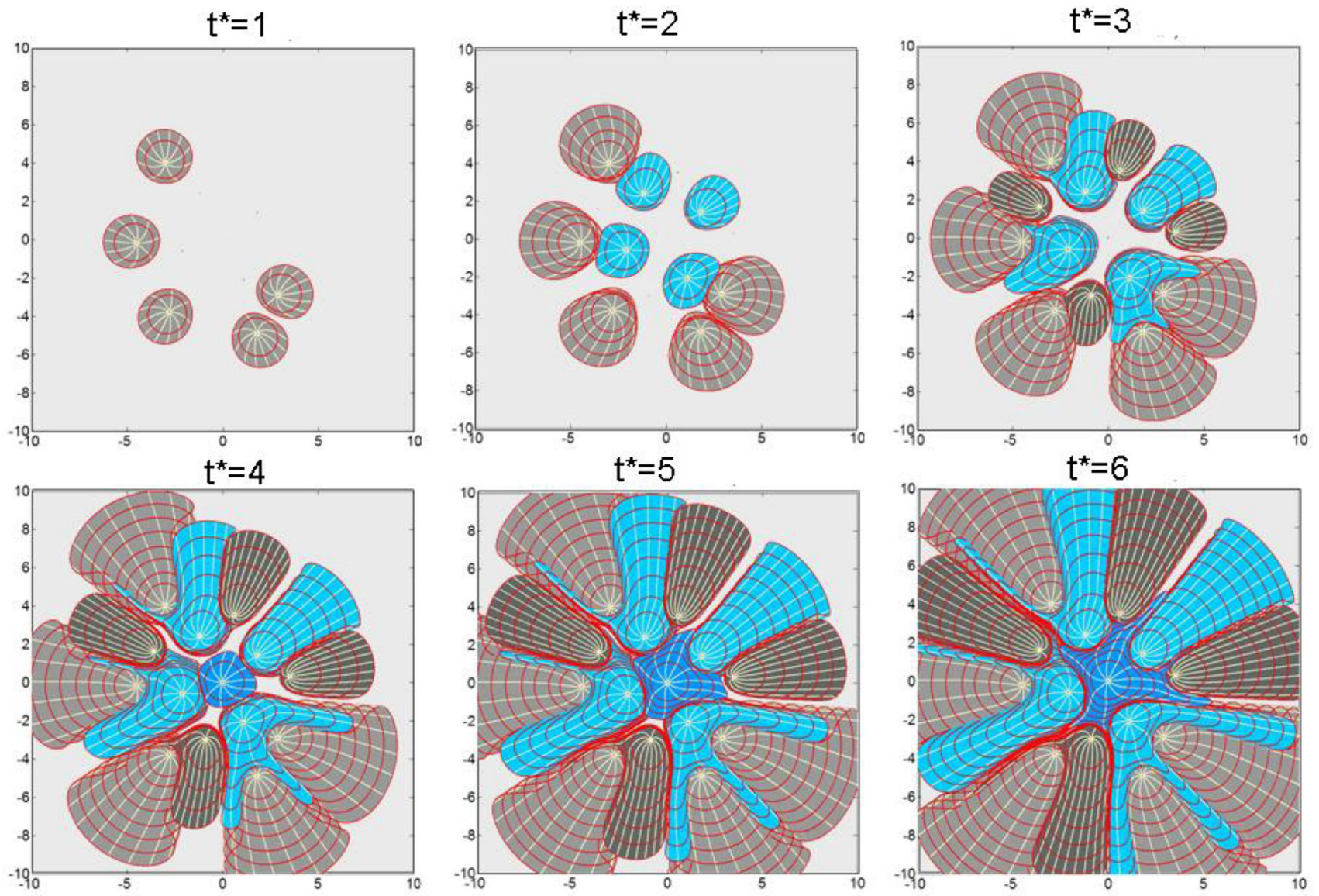

Fig. 16 Infill drilling in reservoir with 14 wells drilled in four clusters: five wells were realized at $t^{*}=0$ (light gray), 4 more at $t^{*}=1$ (light blue), 4 more at $t^{*}=2$ (dark gray), and a final central well at $t^{*}=3$ (dark blue). Total runtime $t^{*}=6$; and contour spacing $t^{*}=0.5$

Slope), West Texas Carbonate waterfloods, Ghawar Field (Saudi Arabia) and Kirkuk (Iraq); (see Lolomari et al. 2000; Xueli et al. 2006; Ghori et al. 2006, 2007). The goal of waterflooding in such fields is enhancing oil recovery, but waterflooding itself is not considered an enhanced oil recovery (EOR) technique; the method is traditionally classified as an improved oil recovery mechanism.

Developing an oil field with water sweep requires an appropriate well architecture and adequate injection rates to ensure optimum sweep area is achieved. To avoid premature water-breakthrough and optimize the sweep of the oil reservoir, the flood pattern must be skillfully managed, which includes:

- Appropriate initial design of the well architecture.

- Appropriate flood and hydrocarbon drainage management.

- Delaying water breakthrough.

- Suppressing water cut after breakthrough.

- Arresting decline of productivity of producer wells.

- Increasing the ultimate recovery.

- Avoidance of cusping.

- Avoiding the occurrence of stranded oil volumes.
We track both the waterflood-advancement contours and flow lines issued from the injector(s), as well as the successive drainage contours for oil around the producer(s) and streamlines moving toward such wells. When a detailed study is made of the spatial and temporal displacements of an advancing waterflood front and the simultaneous pattern of oil-withdrawal timelines, it appears that the flood may sweep the oil in the reservoir either more or less effectively toward the production well depending on, a.o., the specific initial conditions, well pattern and well rates (see "Model results for doublets (direct line drives)", "Model results for 7-spot well patterns", "Arbitrary producer well patterns, infill drilling and peripheral flooding" sections).

\section{Interpretation of model results}

Our systematic modeling of 2-spot (doublets) and 7-spot wells using balanced, underbalanced and overbalanced injection rates revealed new and major insights about effects on sweep efficiency, with and without the presence of an impermeable fault barrier. When a fault is absent, the 
Fig. 17 a Fourteen producer wells with TOFCs for oilwithdrawal as non-dimensional time contours with spacing $t^{*}=0.5$. The speed of fluid particles is determined by the initial flux strength of each producer (all fixed at nondimensional strength $m^{*}=-1$ over the total runtime $t^{*}=3$ ) and the relative position of the sources. b Effect of water flooding on oil-withdrawal pattern using 14 peripheral injectors. c Further expansion of the TOFCs for oil-withdrawal is halted by the water injection (a) No Injection

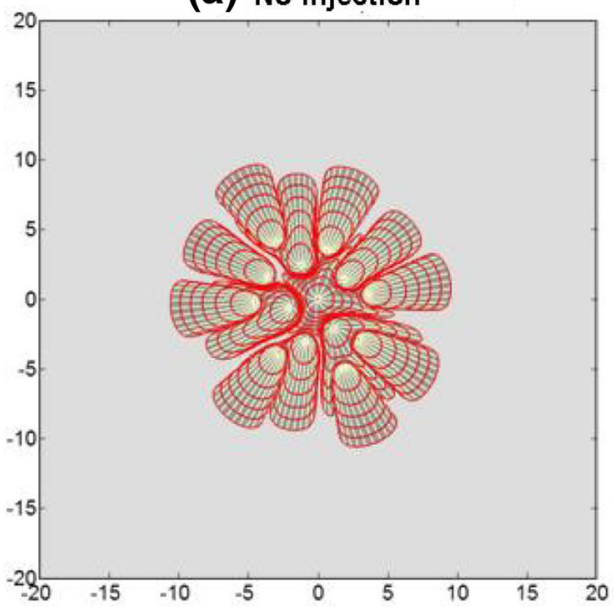

(b) With Injection

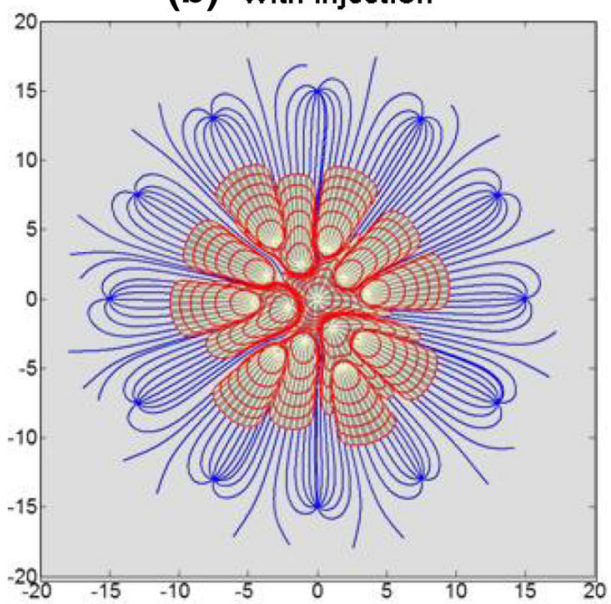

(c) Advanced state

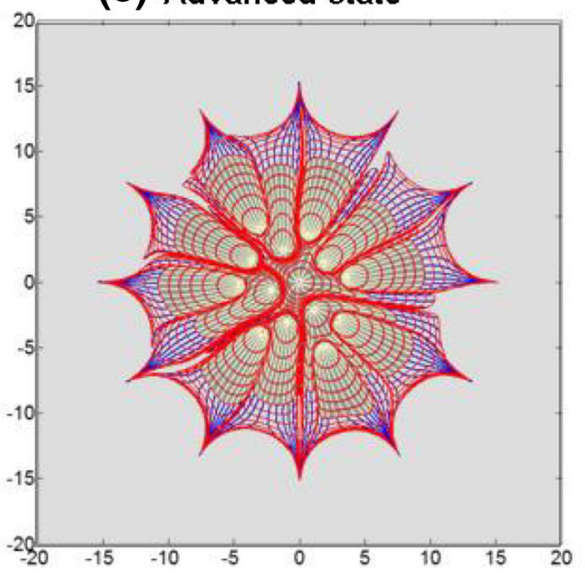

size of the flood area is determined by both the relative rate of the well pair and the distance between the injector well and the flow stagnation point. The distance between the flood flow stagnation point and the injector well [which can be determined using Eq. (3)] provides a good measure for the maximum width of the waterflood (measured normal to the connector of the well pair, this is about twice the stagnation point separation with the injector). Floodwater cannot cross the far-field flow lines and remains confined to an oval region between the stagnation point and the producer well (Fig. 7); the width of the water sweep is limited and related to the stagnation point distance to the injector. When a fault is present, the largest drainage areas will occur around the producer wells that are shielded by the fault from the waterflood (e.g. Figs. 13b, 14b, d).

To evaluate the best injection strategy, the effect of a relatively slow, underbalanced injection rate was systematically investigated. A slower rate of injection relative to the producer will increase the area drained by oil-withdrawal contours. At the same time, only a very small area is swept by the underbalanced flood (Fig. 7a, b). The potentially adverse effects of overbalanced flooding in doublet development must be mitigated either by balanced or underbalanced injection.

The areal width effectively swept by the floodwater grows when the rate of the injector becomes closer to that of the producer. Figure 18 illustrates an example of balanced flooding for a case where a single wellbore hosts both the producing and injection tubes, effectively acting as a point doublet. Around the producer well may occur streamtube regions saturated by the waterflood (Zone 2) and a section that has already produced oil but receives replenishments of far-field oil and therefore will continue to supply more oil to the producer well (Zone 1). From the injector tube, an upper region (Zone 3, away from the producer) is swept by the flood, but this water will only reach the producer long after the water cut has already neared $100 \%$.

\section{Modeling method limitations}

Unlike reservoir simulators based on nonlinear differential equations (finite element, finite difference, and boundary element methods), our method is based on linear 


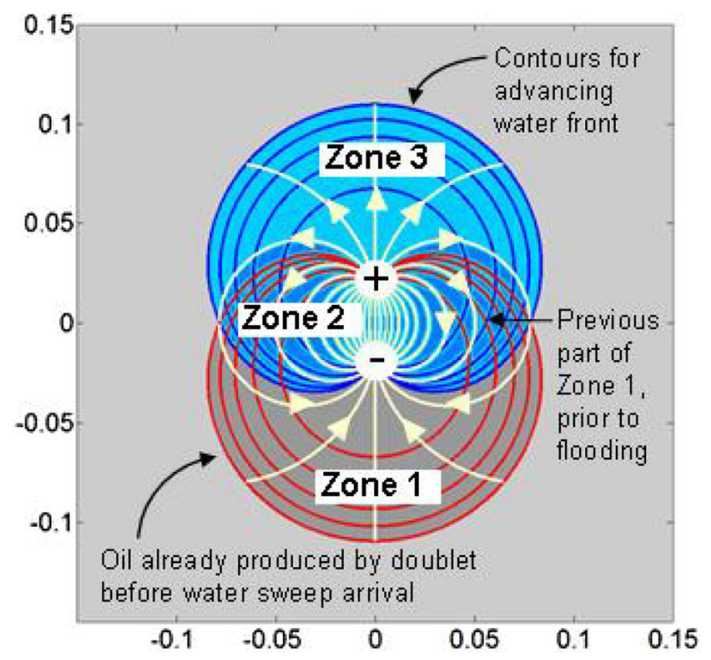

Fig. 18 Single well doublet hosting producer (-) and injector (+) tubes with spacing (d) placed as indicated. The micro-flood immediately mixes water into the producer by doublet flow $\left(d^{*}=0.02\right.$; $m^{*}$ injector $=+1 ; m^{*}$ producer $=-1$, runtime $t^{*}=0.01$, and contour spacing $\left.t^{*}=0.002\right)$. The three types of sweep zones still co-exist

differential equations; all gradients occur in the 2D plane and quasi-steady state is assumed for each velocity field node computed at a certain time step. We assumed infinite lateral flow space, whereas in many real reservoirs complex geological boundaries constrain the flow space. No-flow boundary conditions which may affect the flow field (Sato and Horne 1993a, b) can be accounted for by combining analytical solutions for the basic flows with numerical methods (Sato 2015). Purely analytical descriptions of reservoir flow based on the complex potential can be greatly enhanced by linkage to numerical solutions of imposed boundary conditions that are nonlinear. At least two closely related approaches can be distinguished:

1. A piecewise analytical method using complex potentials each valid for unstructured grid domains that cover internally homogenous sub-regions. Boundary element methods (BEM) are applied to the grid seams to ensure material balance, pressure and flux continuity across the interconnected regions (Hazlett and Babu 2005; Hazlett et al. 2007). The method has capacity to solve 3D streamline paths for multiple wells.

2. Any arbitrary shape of internal and/or external Dirichlet boundaries are defined by selecting a discrete number of critical nodes on such boundaries using an integral equation in what is essentially a collocation technique to generate a sufficient number of equations to solve the number of unknowns (Rokhlin 1983; Kikani and Horne 1992). Internal anisotropy has been solved as a purely analytical expansion (Chirlin 1985) and can be incorporated in such semi-analytical streamline solvers (Sato and Abbaszadeh 1996), commonly referred to as the complex variable boundary element method (CVBEM; Johnson et al. 2014; Sato 2015) but also as perturbation boundary element method (Sato 1992; Sato and Horne 1993a, b). The CVBEM is an alternative to real variable boundary element method (RVBEM) when stream functions and velocity potentials are of interest (Hromadka and Guymon 1984; Hromadka and Lai 1987; Sato and Watanabe 2004).

We believe analytical and semi-analytical streamlinebased reservoir models can support (but not replace) high-fidelity physics models that in some cases take too long run times for a full field model. Computational artifacts can still occur when time steps in particle-path tracking are too coarse, but if the numerical code is cautiously implemented, the analytical solution does not suffer from numerical dispersion. Sector models are possible to estimate sweep patterns between injector and producer paths; well allocation factors, recovery factors and well productivity rates can be quantified for a particular field situation and studied in detail. Our simulator can account for variable injection/production profiles as a function of certain inputs as well as for a range of spatially varying initial conditions (heterogeneities, discontinuities).

\section{Model simplifications}

The complex potential closed-form description of flow is a model approach which like any other model tool requires certain simplifications of the real-world reservoir's physical-parameters-that-matter and boundary conditions (including geometries) to develop an analog system that can predict behavior and responses to variations in input parameters.

We treat a two-phase oil/water system and simplify the phases to have identical physical properties (incompressible, equal viscosities and densities at reservoir conditions). The oil/water interface is assumed to displace piston-like, and there is no spatial/temporal mobility difference.

The analytical simulator has no implicit space constraints and can model cases of both balanced and unbalanced well rates, which we exploit in the present study. We model doublet flow with one injector and one producer for a range of distances and relative well rates (underbalanced, balanced and overbalanced wells-pairs). We show that 2-spot well patterns may result in very different flood sweep regions, depending on the relative rates of the injector and producer wells. Oil-withdrawal and 
Fig. 19 Two ring 7-spot well pattern layout as sketched in Row Ia. Row I Flooding is absent $(m *$ injector $=0$; $m^{*}$ producer $\left.=-1\right)$, Row $I I$ Under-balanced flooding $(m *$ injector $=+1$; $m$ *producer $=-1)$ and Row III Over-balanced flooding $(m *$ injector $=+6$; $m$ *producer $=-1$ ). Runtime for all cases is $t^{*}=10$ and spacing of isochrons is $t^{*}=1$ (a) Water flood
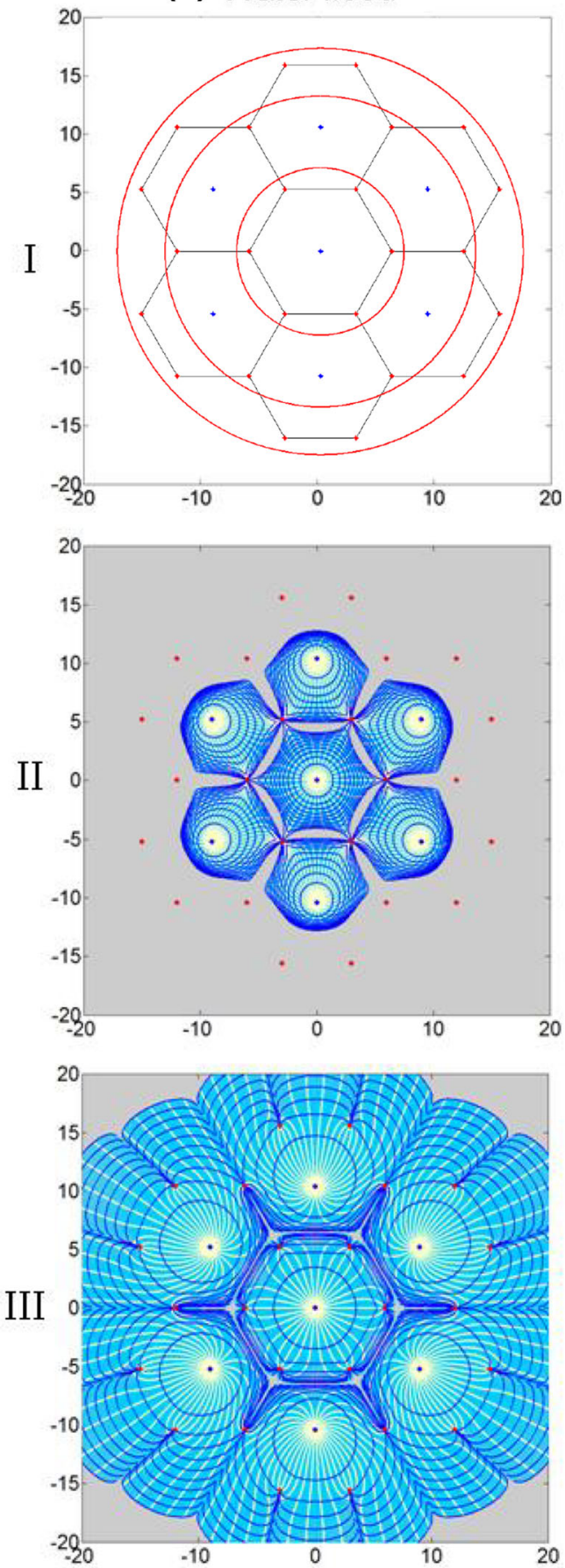

(b) Production

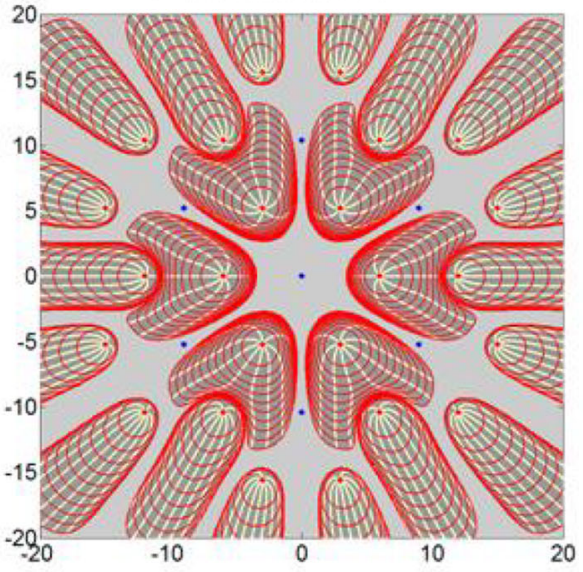

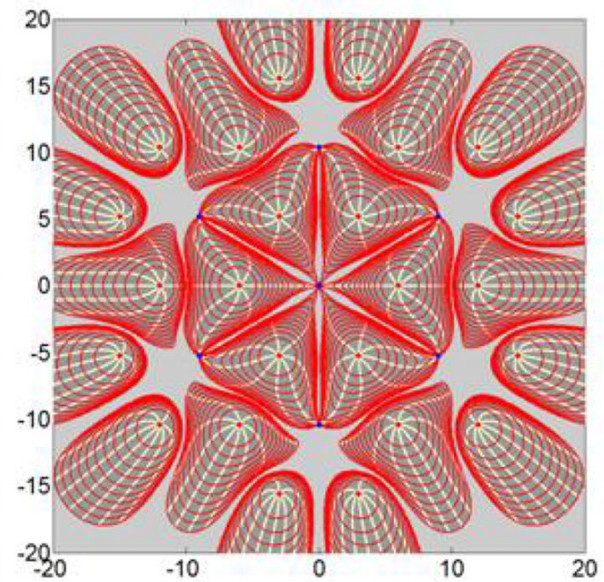

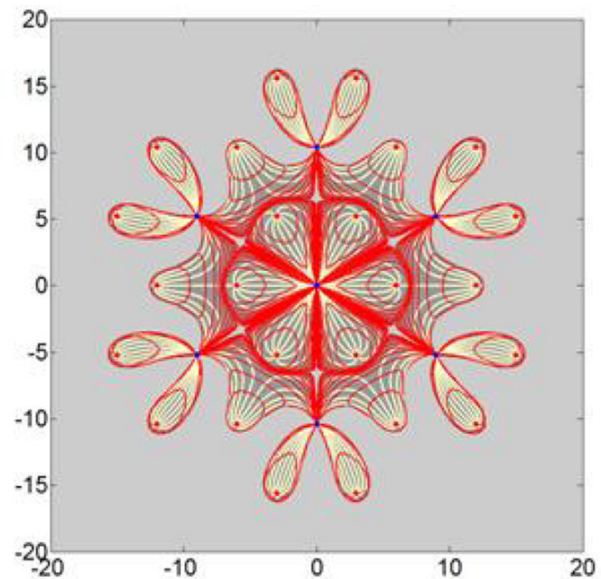

waterflood-advancement contours are visualized for 2-spot (doublets) and 7-spot well patterns, with and without faults. We constrain our approach to vertical wells. Horizontal wells are part of the code options in our reservoir simulator. So-called mixed pattern flood designs (Charles and Startzman 1991; Bedrikovetsky et al. 1995; Ferreira et al. 1996) when either vertical injectors or producers are patterned with horizontal counterparts can also be modeled, but were excluded from the present study for brevity.
Streamline-based reservoir simulations using analytical methods are not compromised by computational up-scaling errors that may complicate numerical methods (Samier et al. 2001). The assumption is that two different fluids (e.g. immiscible oil and water in waterflooding or miscible oil and gas in gas drive) will displace with mobilities that can be modeled by line integrals generated by complex potential descriptions of source and sink flows. The properties of complex potentials and the implied stream 
Fig. 20 Balanced 2-ring 7-spot well pattern. All injectors have $m *$ injector $=+6$. For volumebalancing, production wells in central ring have

$m$ *producer $=-3$, middle ring $m *$ producer $=-2$, and outer ring $m *$ producer $=-1$. For these rates the flower-shaped flood pattern develops (a), and oil-withdrawal is $100 \%$ in the reservoir core-region (b). The shortest distance between injectors and producers is highlighted in (c); any crossflow across these connectors is not possible. Bright spots within each production cell are flow stagnation points. Flood wave and oil-withdrawal contours are superposed in (d); Stream lines in yellow. Runtime for all cases is $t^{*}=10$ and spacing of isochrons is $t^{*}=1$ (a)

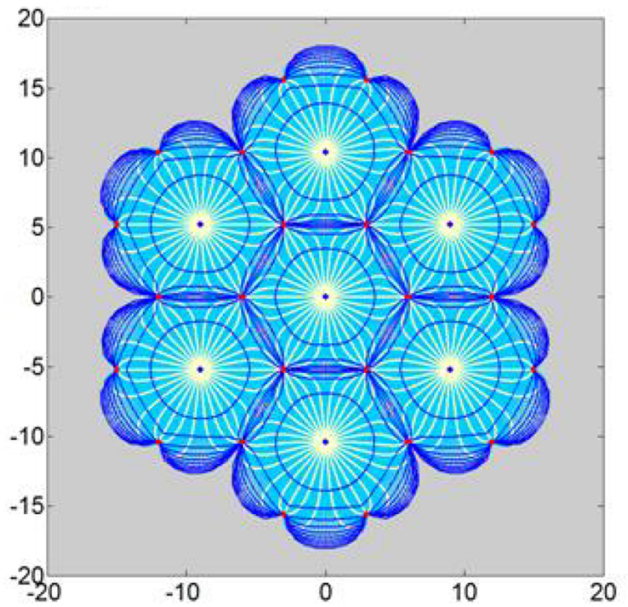

(c)

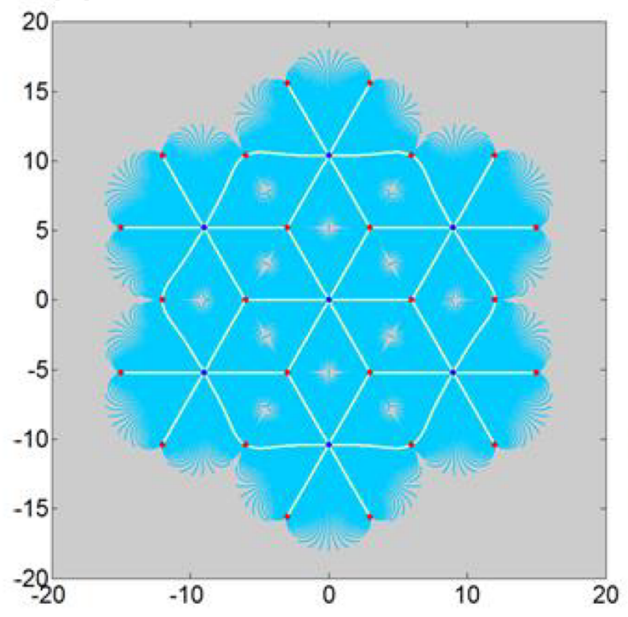

(b)

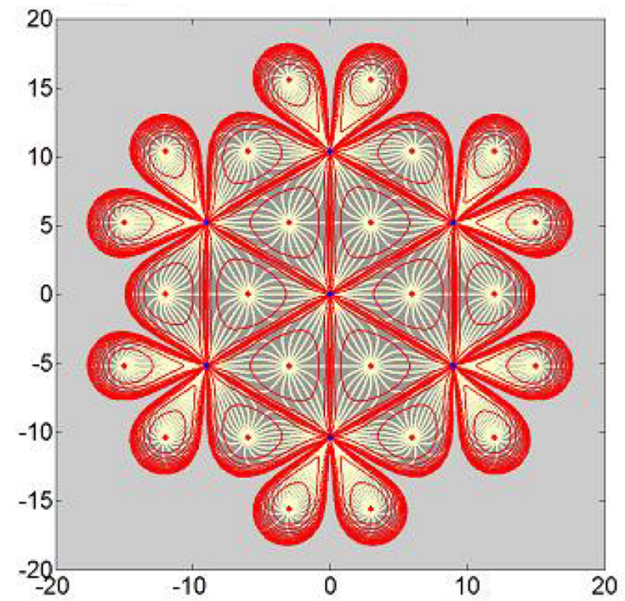

(d)

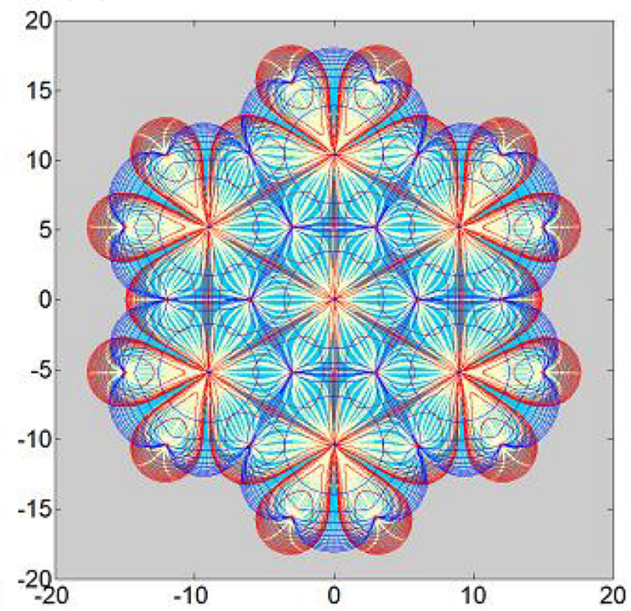

function are that these (1) describe the flow path of fluid particles, (2) determine the instantaneous velocity orientation and magnitude of particles in any location of the flow, and (3) quantify the fluid flux between any selected pair of streamlines (Nelson 1978).

Applications to real field examples require frequent updates for the streamlines, using the sweep geometry resulting from the earlier streamlines as input for the shifted streamlines due to transient flow to account for any wells added and compliant with any actual changes in the flood management schedule (Thiele et al. 2002). Although we use steady well rates in our present analysis, well rates can be time-dependent and prescribed by any decline function to study transient flow. Wells can be switched on at different times with any patterns of decline rate as showcased in a different application of source flows to explain the shapes of terrestrial gravity flows (Weijermars et al. 2014). The resulting particle paths can all be tracked by our method, with the realization that particle paths and instantaneous streamlines will differ in such transient flow cases and both can be accurately accounted for in our model. We can track shifting particle paths for any transient flow in the reservoir with our analytical simulator.

High-fidelity FD reservoir simulators are more appropriate for solving flows including spatial distribution of saturations and pressures over time as a function of PVT fluid properties, permeability and porosity distributions and structural topology of the reservoir. Such models can handle a black oil assumption which implies 3 components (oil, gas, water) and phases (oleic, gas, water) with pressure dependency on phase appearance/disappearance and miscibility between oil and gas.

\section{Conclusions}

The following conclusions can be drawn based on our models. Analytical reservoir streamline simulators can provide useful support for detailed numerical models. Geological discontinuities such as faults and heterogeneities 
Fig. 21 Sketch of 3-ring 7-spot well pattern (a). All injectors have $m *$ injector $=+6$. For volume-balancing, production wells the three inner-most rings have $m^{*}$ producer $=-3$, producers in the outer-most ring have $m^{*}$ producer $=-1$, and the fore-last ring has

$m$ *producer $=-2$. The flowershaped flood pattern develops (b), and oil-withdrawal is $100 \%$ in the field's core-region (c). Streamlines are yellow. Runtime for all cases is $t^{*}=10$ and spacing of isochrons is $t^{*}=1$ (a)

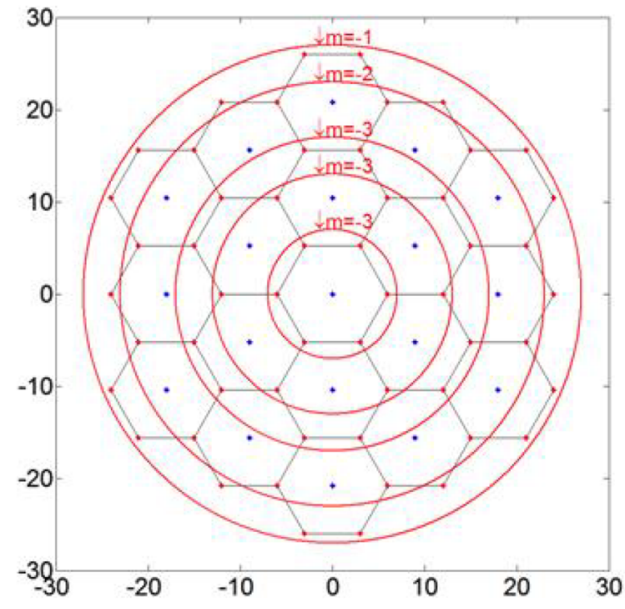

(b)

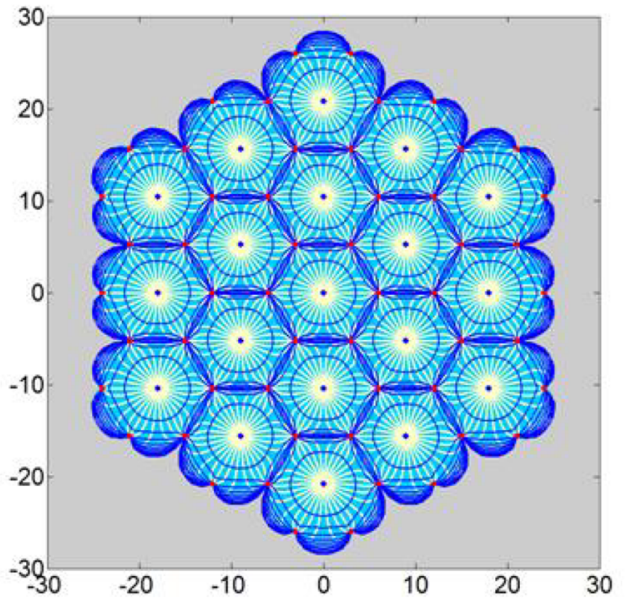

(c)

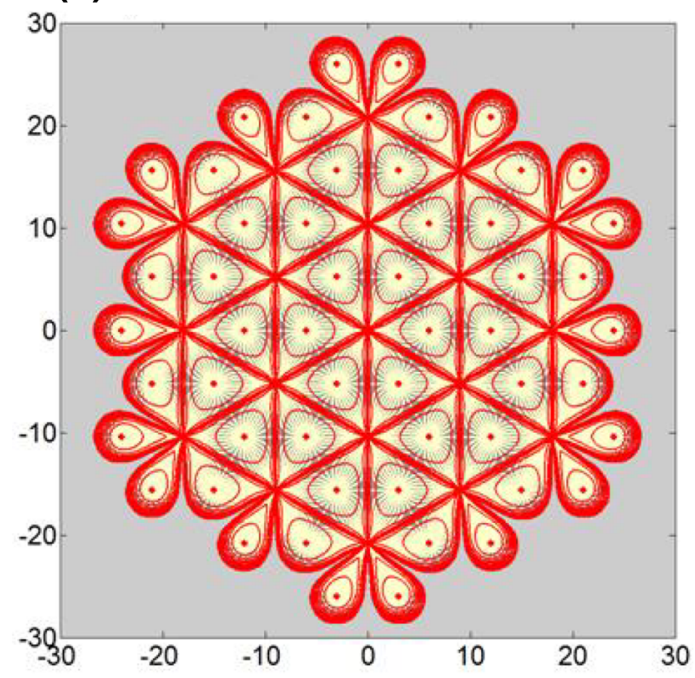

(including gradients in reservoir permeability) can be accounted for in flow solutions. Comparison of well drainage patterns (with and without waterflooding) reveals that the rate of water injection has a profound impact on the areal extent and movement of not only the waterflooding front but also on the oil-withdrawal pattern. The area swept by the flood may bring secondary oil to the well. However, when the injection rate is overbalanced, the producer wells-instead of receiving enhanced recovery of oil-are bypassed by much of both the flood and its oil sweep. When injection rates are underbalanced, producer wells neither receive much effect of any oil sweep as the flooded area shrinks to a small region (independent of the total flood-time). Careful modeling of the flood-induced changes in reservoir Zones 1-3 can help to improve the effects of waterflooding schedules on enhanced oil recovery.

Analytically based methods can rapidly evaluate a range of possible development scenarios and hence are ideally suited for exploring an unlimited range of well architectures to help find plausible field development solution. A major advantage of such models is that only few input data are required, which is particularly useful at the early stages of reservoir characterization; the acquisition of detailed reservoir data is time-consuming and expensive and takes time to acquire. We acknowledge that industry workflow for developed reservoirs is firmly anchored in numerical reservoir simulators that can emulate complex 3D geological heterogeneity, time-dependency of reservoir properties and fluid phase behavior (Datta-Gupta and King 2007). Direct coupling or incorporation of analytical and/or semi-analytical reservoir simulations into such industry simulators is not a practical option. However, analytical simulators are suitable for rapid studies of flow diagnostics such as advocated in independent reservoir simulator approaches (Møyner et al. 2015; Natvig and Lie 2008). 
Fig. 22 Oil-withdrawal patterns in faulted reservoir developed with 2-ring 7-spot well pattern; well rates are mathematically balanced (see caption of Fig. 20 for well rates). Oil-withdrawal contours in red, stream lines in yellow. Fault length and orientation differs for simulations: a $2 l^{*}=6, \mathbf{b}, \mathbf{c} 2 l^{*}=20$. Runtime for all cases is $t^{*}=10$ and spacing of isochrons is $t^{*}=1$ (a)

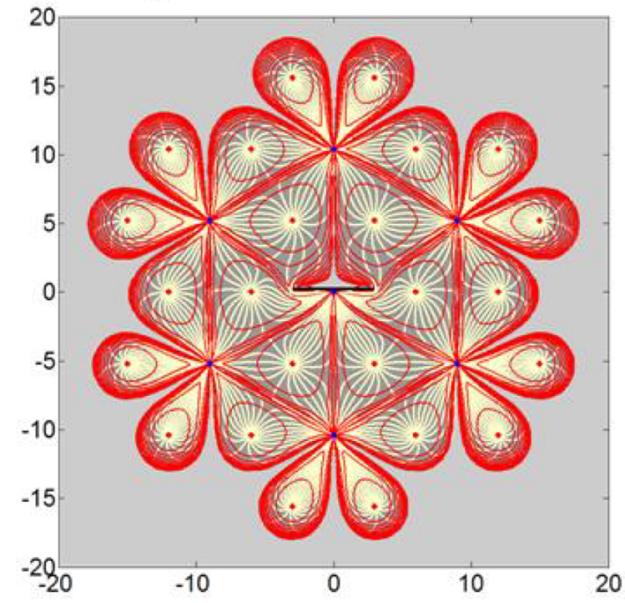

(b)

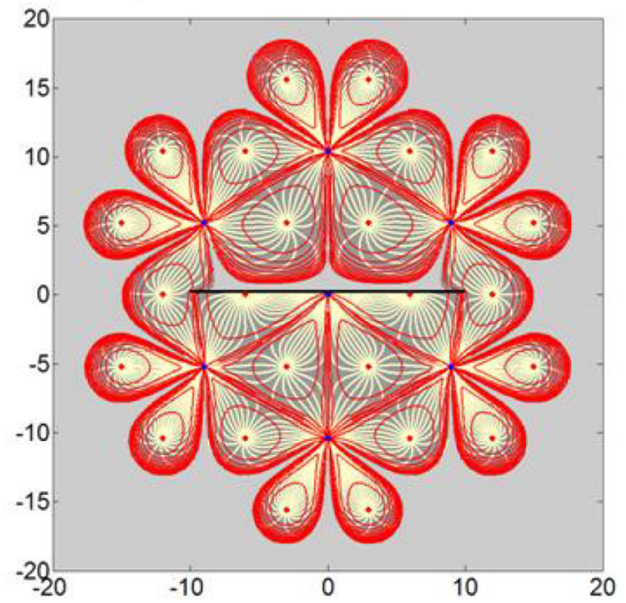

(c)

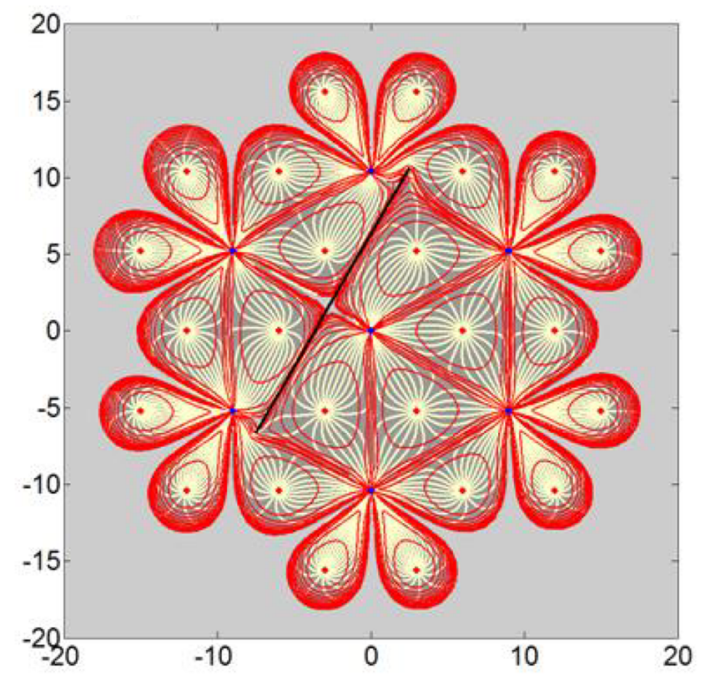

Acknowledgements Our flow visualizations are rendered using MATLAB code which development took approximately 1500 man hours (as to the date of this study's completion). This study was sponsored by Alboran Energy Strategy Consultants, which retains the intellectual rights of the modeling code.

Open Access This article is distributed under the terms of the Creative Commons Attribution 4.0 International License (http:// creativecommons.org/licenses/by/4.0/), which permits unrestricted use, distribution, and reproduction in any medium, provided you give appropriate credit to the original author(s) and the source, provide a link to the Creative Commons license, and indicate if changes were made.

\section{Appendix: Serial well pattern roll-out}

Although early onshore fields in North America and Russia were developed with regular well patterns, fewer options remain due to surface access limitations and/or subsurface discontinuities. Rather than simulating existing fields, we think synthetic cases provide a sound basis for developing systematic conceptual insight. For that purpose, additional simulations of repetitive well patterns were performed to highlight the considerable differences in drainage patterns between peripheral and central wells, with and without waterfloods.

\section{Multiple rings of 7-spot wells}

Developing a particular oil field with a regular 7-spot well pattern takes drilling time. The critical rates for balancing only a single 7-spot are highlighted in Fig. 11. This section investigates the efficiency of the flooding sweep and oilwithdrawal patterns for two or more rings of 7-spot well patterns (e.g., Fig. 19a, Row I).

First consider a 2-ring 7-spot well pattern (seven injectors, 24 producers; Fig. 19). There are three distinct development scenarios. Scenario I (Fig. 19, Row I) is

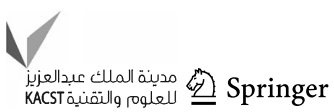


field development without central injection. The central area will preserve a pocket of stranded oil. This pocket persists even if the run time is doubled. However, the peripheral pockets of oil will eventually be produced and disappear.

Scenario II (Fig. 19, Row II) shows a waterflood which is underbalanced. All injectors and producers have equal rates, but their well numbers are unequal, which explains the underbalanced flooding. Oil from the central area is effectively recovered, but other pockets of stranded oil remain (Fig. 19b, Row II).

Scenario III (Fig. 19, Row III) shows field development with overbalanced injection. Overbalanced injection leads to vast over-flooding (Fig. 19a, Row III), where the third, outer ring of producers will produce only minor oil fractions (Fig. 19b, Row III) due to the high water-cut. The flood front sweeps past the outer ring of producers and prematurely terminates effective productivity of the outer wells.

The flooding pattern and corresponding oil-withdrawal contours for a fully balanced 2-ring 7-spot well pattern are given in Fig. 20. Balancing is achieved by setting producer rates such that each producer always receives $1 / 6$ th of the fluid from the connected injectors. Balancing of any regular set of drilling patterns is only possible when rates of producers in the inner and outer rings of the well array are engineered with different well rates (for actual rates, see caption of Fig. 20).

The conclusion from the models in Figs. 19 and 20 is that the highest recovery factor from the reservoir will be realized when the well pattern is drilled first and wells remain capped until all wells are drilled to ensure the sweep and oil-withdrawal patterns are balanced when the production starts. This approach will result in the highest recovery factor. If wells are switched on before the drilling pattern is completed (e.g., Fig. 19), these will require different rates for optimum production when the drilling pattern is expanded and repeated over a larger area (e.g., Fig. 20).

A further expansion of the 7-spot well pattern was simulated using our analytical reservoir simulator for a 3-ring 7 spot (19 injectors, 54 producers; Fig. 21). The pattern was balanced by setting producer flow rates as mandated by the injectors and their location in the field (see caption Fig. 21). Note that producers that were balanced in the two outermost rings of Fig. 20 (for sketch of well pattern see Fig. 19a, Row I) must be assigned different rates when an additional ring of 7-spots is added (Fig. 21). The actual well rates required to maintain balanced flooding are detailed in the caption of Fig. 21 (for comparison with Fig. 20).

\section{Fractured multiple rings of 7 -spot wells}

Insertion of an impermeable fault in the 2-ring 7-spot of Fig. 20 revealed that the presence of any overlooked faults (Fig. 22) may barely alter the oil-withdrawal pattern. The explanation is that the repetitive well pattern forces the stream lines in certain flow paths and discrete faults cannot significantly affect these flow paths (Fig. 22). All producers receive a significant volume of floodwater. This result is unlike faults in single 7 -spots, where any faults may shield certain producers, which has a profound effect on the productivity of such wells (Figs. 13, 14).

\section{References}

Abbaszadeh-Dehghani M (1982) Analysis of unit mobility ratio wellto-well tracer flow to determine reservoir heterogeneity. Ph.D. dissertation, Stanford University, California

Abou-Kassem JH, Aziz K (1985) Analytical well models for reservoir simulation. SPE J 25(04):573-579. doi:10.2118/11719-PA

Albertoni A, Lake LW (2003) Inferring interwell connectivity only form well-rate fluctuations in waterfloods. SPE Res Eval Eng 6(2):6-16. doi:10.2118/83381-PA

Al-Najem AA, Siddiqui S, Soliman M, Yuen B (2012) Streamline simulation technology: evolution and recent trends. Paper SPE 160894 presented at the SPE Saudi Arabia section technical symposium and exhibition, Al-Khobar, 8-11 April. doi:10.2118/ 160894-MS

Bar-Meir G (2013) Basics of fluid mechanics (version 0.3.4.0). Chicago, p 664. http://www.potto.org/downloads.php

Batycky RP, Thiele MR, Baker RO, Chugh SH (2005) Revisiting reservoir flood-surveillance methods using streamlines. SPE Res Eval Eng 11(2):387-394. doi:10.2118/95402-PA

Bear J (1972) Dynamics of fluids in porous media. Elsevier, New York (repr. Dover, 1988)

Bedrikovetsky PG, Magarshak TO, Shapiro AA (1995) Waterflooding in a system of horizontal wells (Analytical reservoir model. Offshore case). Paper SPE 29876 presented at the Middle East Oil Show, Bahrain, 11-14 March. doi:10.2118/29876-MS

Charles DD, Startzman BA (1991) Streamtube modeling of horizontal wells in mixed pattern waterfloods. Paper SPE 23451 presented at the SPE Eastern Regional Meeting, Lexington, Kentucky, 22-25 October. doi:10.2118/23451-MS

Chirlin GR (1985) Flow through a porous medium with periodic barriers or fractures. SPE J 25(03):358-362. doi:10.2118/11595-PA

Cox DO (1987) Waterflood performance estimation with a layered streamtube model. Paper SPE 16489 presented at the petroleum industry application of microcomputers, Lake Conroe, Texas, 23-26 June. doi:10.2118/16489-MS

Craig FG (1970) The reservoir engineering aspects of waterflooding, vol 3. Henry L. Doherty Series, SPE

Datta-Gupta A (2000) Streamline simulation: a technology update. Distinguished author series. J Pet Technol 52(12):68-84. doi:10. 2118/65604-JPT

Datta-Gupta A, King MK (2007) Streamline simulation: theory and practice. Textbook Series, SPE, Richardson

Dougherty EL (1963) Mathematical model of an unstable miscible displacement. SPE J 3(02):155-163. doi:10.2118/509-PA 
Dougherty EL, Sheldon JW (1964) The use of fluid-fluid interfaces to predict the behavior of oil recovery processes. SPE J 4(02):171-182. doi:10.2118/781-PA

Doyle RE, Wurl TM (1971) Stream channel concept applied to waterflood performance calculations for multiwell, multizone, three-component cases. J Pet Technol 23(03):373-380. doi:10. 2118/2653-PA

Ferreira H, Mamora DD, Startzman RA (1996) Simulation studies of waterflood performance with horizontal wells. Paper SPE 35208 presented at the Permian basin oil and gas recovery conference, Midland, 27-29 March. doi:10.2118/35208-MS

Ghori SG, Syed ZJ, Vohra IR, Lin C (2006) Improving injector efficiency using streamline simulation: a case study of waterflooding in Saudi Arabia. Paper SPE 93031 presented at the SPE/ DOE symposium on improved oil recovery, Tulsa, Oklahoma, 22-26 April. doi:10.2118/93031-MS

Ghori SG, Jilani SZ, Alhuthali A, Krinis D, Kumar ATA (2007) Improving injector efficiencies using streamline simulation: a case study in a giant middle east field. Paper SPE 105393 presented at the middle east oil and gas show and conference, Kingdom of Bahrain, 11-14 March. doi:10.2118/105393-MS

Haitjema HM (1995) Analytic element modeling of groundwater flow. Academic Press, San Diego

Hauber WC (1964) Prediction of waterflood performance for arbitrary well patterns and mobility ratios. J Pet Technol 16(1):95-103. doi:10.2118/756-PA

Hazlett RD, Babu DK (2005) Optimal well placement in heterogeneous reservoirs through semi-analytical modeling. SPE J 10(3):286-296. doi:10.2118/84281-PA

Hazlett RD, Babu DK, Lake L (2007) Semi-analytical streamfunction solutions on unstructured grids for flow in heterogeneous media. SPE J 12(02):179-187. doi:10.2118/95913-PA

Heidt JM, Follensbee GJ (1971) Application of the Higgins-Leighton waterflood prediction technique to halfway reservoirs in Northeastern British Columbia. J Can Pet Technol 10(01):23-28. doi:10.2118/71-01-02

Hewett T, Behrens R (1991) Scaling laws in reservoir simulation and their use in a hybrid finite difference/streamtube approach to simulating the effects of permeability heterogeneity. In: Lake L, Carroll Jr. HB, Wesson TC (eds) (1991) Reservoir characterization II. Academic Press, Inc, London

Higgins RV, Leighton AJ (1962a) A computer method to calculate two-phase flow in any irregularly bounded porous medium. J Pet Technol 14(06):679-683. doi:10.2118/243-PA

Higgins RV, Leighton AJ (1962b) Computer prediction of water drive of oil and gas mixtures through irregularly bounded porous media three-phase flow. J Pet Technol 14(09):1048-1054. doi:10.2118/283-PA

Higgins RV, Boley DW, Leighton AJ (1964) Aids to forecasting the performance of water floods. J Pet Technol 16(09):1076-1082. doi:10.2118/851-PA

Hromadka TV, Guymon GL (1984) The complex variable boundary element method: development. Int $J$ Numer Meth Eng 20(01)25-37. doi:10.1002/nme.1620200104

Hromadka TV, Lai C (1987) The complex variable boundary element method in engineering analysis. Springer, New York

Johnson AN, Hromadka TV, Caroll M, Hughes M, Jones L, Pappas N, Thomasy C, Horton S, Whitely R, Johnson M (2014) A computational approach to determining CVBEM approximate boundaries. Eng Anal Bound Elem 41:83-89. doi:10.1016/j. enganabound.2013.12.011

Kikani J, Horne RN (1992) Pressure-transient analysis of arbitrarily shaped reservoirs with the boundary-element method. SPE Form Eval 7(01):53-60. doi:10.2118/18159-PA

King MJ, Blunt MJ, Mansfield MM, Christie MA (1993) Rapid evaluation of the impact of heterogeneity on miscible gas injection. Paper SPE 26079 presented at the Western Regional Meeting, Anchorage, Alaska, 26-28 May. doi:10.2118/26079MS

Lake LW (1989) Enhanced oil recovery, 1st edn. Prentice Hall, Englewood Cliffs

Lake JR, Holstein ED (2007) Petroleum engineering handbook, vol 5. Reservoir engineering and petrophysics. SPE

LeBlanc JL, Caudle BH (1971) A streamline model for secondary recovery. SPE J 11(01):7-12. doi:10.2118/2865-PA

Lolomari T, Bratvedt K, Crane M, Milliken WJ, Tyrie JJ (2000) The use of streamline simulation in reservoir management: methodology and case studies. Paper SPE 63157 presented at the annual technical conference and exhibition, Dallas, 1-4 Ocotber. doi:10. 2118/63157-MS

Martin JC, Wegner RE (1979) Numerical solution of multiphase, twodimensional incompressible flow using streamtube relationships. SPE J 19(05):313-323. doi:10.2118/7140-PA

Martin JC, Woo PT, Wagner RE (1973) Failure of stream tube methods to predict waterflood performance of an isolated inverted five-spot at favorable mobility ratios. J Pet Technol 25(02):151-153. doi:10.2118/4346-PA

Masukawa J, Horne RN (1988) Application of the boundary integral method to immiscible displacement problems. SPE Res Eng 3(03):1069-1077. doi:10.2118/15136-PA

Morel-Seytoux HJ (1965) Analytical-numerical method in waterflooding predictions. SPE J 5(03):247-258. doi:10.2118/985-PA

Moreno J, Kazemi H, Gilman JR (2004) Streamline simulation of countercurrent water-oil and gas-oil flow in naturally fractured dual-porosity reservoirs. Paper SPE 89880 presented at the SPE annual technical conference and exhibition, Houston, 26-29 September. doi:10.2118/89880-MS

Møyner O, Krogstad S, Lie K-A (2015) The application of flow diagnostics for reservoir management. SPE J 20(02):306-323. doi:10.2118/171557-PA

Muskat M (1949a) Physical principles of oil production. McGrawHill, New York

Muskat M (1949b) The theory of potentiometric models. In: Transactions of the AIME, vol 179, part, 216-221. Society of Petroleum Engineers, Richardson. doi:10.2118/949216-G

Muskat M, Wyckoff RD (1934) A Theoretical analysis of waterflooding networks. In: Transactions of the AIME, vol 107, part I, 62-76. Texas: Society of Petroleum Engineers, Richardson. doi:10.2118/934062-G

Natvig JR, Lie K-A (2008) Fast computation of multiphase flow in porous media by implicit discontinuous Galerkin schemes with optimal ordering of elements. J Comput Phys 227(24):10108-10124. doi:10.1016/j.jcp.2008.08.024

Nelson R (1978) Evaluating the environmental consequences of groundwater contamination: 2. Obtaining location/arrival time and location/outflow quantity distributions for steady flow systems. Water Resour Res 14(3):416-428. doi:10.1029/ WR014i003p00416

Nilsen HM, Lie K-A (2009) Front-tracking methods for use in streamline simulation of compressible flow. Paper SPE 119099 presented at the SPE reservoir simulation symposium, The Woodlands, 2-4 February. doi:10.2118/119099-MS

Peddibhotla S, Spath J, Batycky RP (1997) An efficient PC based streamline simulator for immiscible and miscible displacements. Paper SPE 38129 presented at the SPE petroleum computer conference, Dallas, 8-11 June. doi:10.2118/38129-MS

Pizarro JODS, Branco CCM (2012) Challenges in implementing an EOR project in the pre-salt province in deep offshore Brasil. Paper SPE 155665 presented at the SPE EOR conference at oil and gas West Asia, Muscat, 16-18 April. doi:10.2118/155665-MS

Rokhlin V (1983) Rapid solution of integral equations of classical potential theory. J Comput Phys 60:187-207

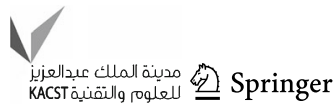


Rubinstein J, Torquato S (1989) Flow in random porous media: mathematical formulation, variational principles, and rigorous bounds. J Fluid Mech 206:25-46. doi:10.1017/S0022112089002211

Samier P, Quettier L, Thiele M (2001) Applications of streamline simulations to reservoir studies. Paper SPE 66362 presented at the SPE reservoir simulation symposium, Houston, 11-14 February. doi:10.2118/66362-MS

Sato K (1992) Accelerated perturbation boundary element model for flow problems in heterogeneous reservoirs. Ph.D. Thesis, Stanford University, p 199

Sato K (2015) Continuum analysis for practical engineering. Springer, London, p 300

Sato K, Abbaszadeh M (1996) Tracer flow and pressure performance of reservoirs containing distributed thin bodies. SPE Form Eval 11(03):185-193. doi:10.2118/28444-PA

Sato K, Horne RN (1993a) Perturbation boundary element method for heterogeneous reservoirs: part 1. Steady-state flow problems. SPE Form Eval 8(04):306-314. doi:10.2118/25299-PA

Sato K, Horne RN (1993b) Perturbation boundary element method for heterogeneous reservoirs: part 2. Transient flow problems. SPE Form Eval 8(04):315-322. doi:10.2118/25300-PA

Sato K, Watanabe Y (2004) Treatment of Neumann boundaries in complex variable boundary element method. Commun Numer Method Eng 20:119-132. doi:10.1002/cnm.654

Sheldon J, Dougherty E (1964) A numerical method for computing the dynamical behavior of fluid-fluid interfaces in permeable media. SPE J 4(02):158-170. doi:10.2118/780-PA

Shin DH, Sharma MM (2014) Factors controlling the simultaneous propagation of multiple competing fractures in a horizontal well. Paper SPE 168599 presented at the SPE hydraulic fracturing technology conference, The Woodlands, 4-6 February. doi:10. 2118/168599-MS

Strack ODL (1989) Groundwater mechanics. Prentice-Hall, Englewood Cliffs

Thiele MR (1994) Modeling multiphase flow in heterogeneous media using streamtubes. Ph.D. Thesis, Stanford University

Thiele MR, Batycky RP, Blunt MJ, Orr FM Jr (1996) Simulating flow in heterogeneous systems using streamtubes and streamlines. SPE Res Eng 11(01):5-12. doi:10.2118/27834-PA

Thiele MR, Batycky RP, Thomas LK (2002) Miscible WAG simulations using streamlines. Paper presented at the 8th European conference on the mathematics of oil recovery (ECMOR), Freiberg, 3-6 September 2002
Tiab D, Dinh AV (2013) Analytical determination of interwell connecivity based on flow rate fluctuations in waterflood reservoirs. Paper SPE 164481 presented at the SPE production and operations symposium, Oklahoma City, Oklahoma, 23-26 March. doi:10.2118/164481-MS

Towler BF (2002) Fundamental principles of reservoir engineering, vol 8. SPE Textbook Series, SPE

Weijermars R (2014) Visualization of space competition and plume formation with complex potentials for multiple source flows: some examples and novel application to Chao lava flow (Chile). J Geophys Res 119(3):2397-2414. doi:10.1002/2013JB010608

Weijermars R, Schmeling H (1986) Scaling of Newtonian and nonNewtonian fluid dynamics without inertia for quantitative modelling of rock flow due to gravity (including the concept of rheological similarity). Phys Earth Planet Int 43(4):316-330. doi:10.1016/0031-9201(86)90021-X

Weijermars R, van Harmelen A (2016) Breakdown of doublet recirculation and direct line drives by far-field flow: implications for geothermal and hydrocarbon well placement. Geophys J I (GJIRAS) 206(01):19-47. doi:10.1093/gji/ggw135

Weijermars R, Dooley TP, Jackson MPA, Hudec MR (2014) Rankine models for time-dependent gravity spreading of terrestrial source flows over subplanar slopes. J Geophys Res Solid Earth 119(9):7353-7388. doi:10.1002/2014JB011315

Weijermars R, Van Harmelen A, Zuo LH (2016) Controlling flood displacement fronts using a parallel analytical streamline simulator. J Petrol Sci Eng 139:23-42. doi:10.1016/j.petrol.2015.12. 002

Willhite GP (1986) Waterflooding, vol 3. SPE Textbook Series

Wyckoff RD, Botset HG, Muskat M (1933) Mechanics of porous flow-applied to water-flooding problems. Trans AIME 103:219-249. doi:10.2118/933219-G (Society of Petroleum Engineers)

Xueli L, Yang J, Li Z, Wang Y (2006) A new methodology on reservoir modelling in the fracture-cavity carbonate rock of tahe oilfield. Paper SPE 104429 presented at the international oil and gas conference and exhibition in China, Beijing, 5-7 December. doi:10.2118/104429-MS

Zandvliet MJ (2008) Model-based lifecycle optimization of well locations and production settings in petroleum reservoirs. Ph.D. dissertation, Technische Universiteit Delft, Delft 